\title{
The Structure and Dynamics of International Development Assistance
}

\section{Citation}

Coscia, Michele, Ricardo Hausmann, and César A. Hidalgo. "The Structure and Dynamics of International Development Assistance." Journal of Globalization and Development 3.2 (March 2013): 1-42.

\section{Published Version}

http://dx.doi.org/10.1515/jgd-2012-0004

\section{Permanent link}

http://nrs.harvard.edu/urn-3:HUL.InstRepos:10649346

\section{Terms of Use}

This article was downloaded from Harvard University's DASH repository, and is made available under the terms and conditions applicable to Other Posted Material, as set forth at http:// nrs.harvard.edu/urn-3:HUL.InstRepos:dash.current.terms-of-use\#LAA

\section{Share Your Story}

The Harvard community has made this article openly available.

Please share how this access benefits you. Submit a story.

Accessibility 


\title{
Michele Coscia*, Ricardo Hausmann and César A. Hidalgo The Structure and Dynamics of International Development Assistance
}

\begin{abstract}
We study the structure of international aid coordination by creating and analyzing a tripartite network of donor organizations, recipient countries and development issues using web-based information. We develop a measure of coordination and find that it is moderate, achieving about $60 \%$ of its theoretical maximum. Many countries are strongly connected to organizations that are related to the issues that are salient there. Nevertheless, we identify many countries that are poorly served, issues that are inadequately attended to, and organizations that focus on the wrong combination of places and issues. Our approach may be used to improve decentralized coordination.
\end{abstract}

Keywords: aid coordination; development assistance; network science.

*Corresponding author: Michele Coscia, Center for International Development, Harvard University, 79 JFK St, Cambridge, MA 02138, USA, e-mail: michele_coscia@hks.harvard.edu Ricardo Hausmann: Center for International Development, Harvard University; Harvard Kennedy School, Harvard University, 79 JFK St, Cambridge, MA 02138, USA,; and Santa Fe Institute, Santa Fe, NM, USA

César A. Hidalgo: Center for International Development, Harvard University Macroconnections @ MIT Media Lab, 77 Mass. Ave., E14/E15 Cambridge, MA 02139-4307, USA

\section{Introduction}

This paper explores the structure of international development assistance by creating a tri-partite network composed of aid organizations, countries of interest and development issues. The network was constructed using online data on the co-occurrence of pairs of organizations, countries and issues in the websites of development agencies and in the World Wide Web. We compare the structure of networks connecting countries to issues, countries to organizations and organizations to issues, to assess the degree to which the system is able to match a country with organizations that have expertise in the issues that are salient in that country. More generally, this paper extends the use of data-mining tools and network science to the study of decentralized networks of organizations, which is an area that hitherto eluded empirical analysis. 
International development assistance became an explicit policy issue in the 1940s. It arose from two fundamental changes to the global economy: the Great Divergence (Pritchett 1997) and the proliferation of states. Over the past two centuries, incomes across countries and regions of the world have greatly diverged, from a ratio of about 4 to 1 in 1820 to a ratio of over 100 to 1 at present (Maddisson 2008). Initially, these rising gaps occurred under colonialism. Income gaps grew within large multi-ethnic empires, such as that of the British or the French. It was then that Rudyard Kipling (1899) wrote about the White Man's Burden, based on the idea that it was the responsibility of Western empires to raise the level of development of their poorer possessions. In France, the organizing principle was "Le Rayonnement de la France," the illumination of the Asian, African and Caribbean possessions of the French Empire from its culturally-sunny and ethnically French core.

After World War II, however, the decolonization process led to the dismemberment of the British and French empires and a concomitantly rapid increase in the number of new sovereign states. The large and widening income gaps now occurred between, rather than within, sovereign nations. The term "international" in "international development," therefore, highlighted the fact that it was no longer about sovereigns managing their possessions, but about rich ones trying to help poorer ones catch up.

One part of the international development effort was organized multilaterally through either the United Nations or the Bretton Woods organizations (i.e., the IBRD, a.k.a. the World Bank, the IMF and the GATT'1). Simultaneously, rich countries developed their own international development efforts, which lead to bilateral organizations such as USAID (for the US), DFID (UK), CIDA (Canada), SIDA (Sweden), where the acronym ID stands for International Development and the letter A for Agency. Other nations preferred to use the term "cooperation" instead of "development" for their bilateral efforts. These include the Japanese, Koreans, Spaniards and the Dutch.

In addition to official multilateral and bilateral organizations, private philanthropic organizations had emerged from Church groups (e.g., CARE), wealthy individuals (e.g., Rockefeller, Ford, Gates), action-oriented groups (e.g., Medecins Sans Frontier, ACCION International) and name-and-shame organizations (e.g., Human Rights Watch). Moreover, starting around 1960, in different continents, regional multilateral development banks were formed, modeled on the World Bank. This was the case of the AfDB, ADB and IADB, and more recently the EBRD. As a consequence, during the last 60 years the number of organizational actors in

1 For simplicity, we name organizations through their well-known acronyms. A list of acronyms and the organizational names is included in Table 1. 
international development has greatly expanded, giving rise to a very diverse set of organizations that now need to coordinate their efforts.

The expansion, however, has not been limited only to the number of actors, but has also included the content of the issues at hand. Initially, the intellectual interpretation of the obstacles to development focused on the availability of capital and infrastructure. The successful experience of the Marshall Plan in Europe (1948-1952) suggested that this was an appropriate approach. The application of the same strategy through the IBRD in other parts of the world, however, led to disappointment, and the revised strategies identified a widening list of potential obstacles to development, including issues such as education, public health, demographic pressures, industrial bottlenecks, macroeconomic stability, appropriate market regulation, environmental sustainability, human rights, institutional quality, governance, inequality and gender gaps, among many others. As a consequence, different specialized topics were recognized as important and were buttressed by dedicated organizations and programs. The UN system responded by creating specialized bodies for different purposes such as the WHO (for health), UNESCO (education), UNIDO (industrial development), FAO (for agriculture and food security), UNDP (technical assistance for development), UNCTAD (trade), ILO (labor), UNHCR (human rights and refugees), etc. Concomitantly, the regional organizations created similar structures (e.g., the Organization of American States, the Pan-American Health Organization, ASEAN, Organization for African Unity).

Within the developed countries, governments started to involve an increasing number of ministries and departments, beyond their development agencies, in international cooperation efforts, in order to make available their areas of expertise, such as financial regulation, tax administration and health. For example, in the USA, some 14 different departments run development assistance programs. Within developing countries, a tendency towards decentralization of administration and authority led to more independent state and local governments with responsibility for many of the development projects.

Hence, economic divergence, decolonization, decentralization and the changing conceptual framework resulted in an increasing number of donors, recipients and issues, making international development a truly complex undertaking. The world now has hundreds of official aid organizations and thousands of private organizations working in over 140 sovereign states and many more subnational governments. According to the Directory of Development Organization there are more than 72,000 related organizations around the world. ${ }^{2}$ The multiplication of donors, recipients and issues implies a network with hundreds of millions of possible connections.

2 http://www.devdir.org/stats.htm, May 30th, 2012. 
With the emergence of this increasingly complex structure, questions of coordination rose to the fore. How could donor organizations know which recipient organizations to work with and on what issues? How could donor organizations be sure that they were creating value rather than just duplicating the efforts of others? How could organizations be accountable for results if so many other players were involved in the process? How should resources be allocated across countries and topics? How could resources be allocated to the most effective organizations within each topic? How could political parties in donor countries support the use of public resources for international development if the beneficiaries could not be held accountable for results?

Given these challenges, the issue of aid coordination has become central to the whole development effort. One such coordinating tool is the convening of so-called consultative groups or roundtables. A Google search of the term "consultative group," for instance, finds some 3.4 million pages. The conjunction of the terms "roundtable" + "aid" + "development" generates more than 10 million pages, while the term "aid coordination" generates more than 420,000 pages.

The purpose of this paper is to map the network of international aid efforts, quantify its structure and assess its performance. To do this, we use techniques that exploit the footprints left by the aid efforts on the web. We find that the aid community is held together by large, diversified organizations, which act as hubs that connect to smaller more specialized entities. This defines a more horizontal structure with large hubs where the distance between organizations is smaller than in a hierarchy. Also, aid organizations tend to organize their efforts geographically, except when dealing with the very large developing countries. Finally, aid organizations tend to care about the issues that are important for the countries they care about, although important misalignments are present, as we illustrate below.

\section{Centralized vs. Decentralized Coordination}

Centralized coordination requires hierarchies. Decentralized coordination lead to networks that are more horizontal. Decentralized coordination is not a new problem in economics. A founding idea of economics is the invisible hand: the notion of a decentralized process where agents following their own goals lead to systemic self-organization. Much of economics is focused on the study of the potential inefficiencies of self-organizing market coordination (e.g., missing markets, non-convexities, imperfect information, externalities, etc.) and of the policies that may facilitate improved outcomes. The discussion of economic 
coordination reappeared after the Bolshevik Revolution, with questions regarding the viability of central planning. In the view of von Misses and Hayek (Hayek 1929, 1945), the issue hinged on an information problem. Markets can be seen as computing devices that can assess whether a particular good has a social value worth more than its inputs, and hence, worthwhile to be produced. In this view, markets mobilize information regarding relative preferences, subjective valuations and alternative production techniques that is decentralized among potentially many producers and consumers. By contrast, a central planner has no alternative process to gather and process this information and hence cannot do a decent coordination job. While some formal models were developed to prove the potential efficiency of central planning, with a fixed set of goods and technologies (e.g., Lange 1949; Kornai and Liptak 1965), the literature died out after it became clear that the central planner could hardly explore a set of expanding technological possibilities in the way that Schumpeterian entrepreneurs could. This became patently obvious in the comparison of product diversity and technological progress between the East and West during the Cold War (Kornai 1992).

Aid coordination faces a similar dilemma to that of markets: the choice between centralized control vs. self-organization. The coordination problem consists in the fact that there are many potential sources of supply and demand for a large set of alternative development goods. Aid organizations have goals that may or may not be altruistic, recipient agencies may be advancing national or particular interests and the transaction may involve a grant, a loan or technical assistance. The details of the transaction are less important than the fact that, whatever are the goals of each organization, only certain types of transactions will take place that are agreeable to both parties and their "authorizing environments" (Moore 1997). One can imagine a situation in which some central entity, at the global or national level, controls the process and allocates roles and tasks. For example, the current de jure approach to aid coordination, as framed by the Paris Declaration for Aid Effectiveness (2005) and the Accra Agenda for Action (2008) starts with an international agreement on the substantive targets to be achieved, namely, the millennium development goals (MDGs). Given these objectives, countries must then write a Poverty Reduction Strategy Paper, which is supposed to serve as a mechanism for donor coordination. This paper should be reviewed by the different domestic constituencies and be consistent with the achievement of the agreed MDGs. Once the paper is ready, roundtables and consultative groups are convened to allocate roles and functions to the different development partners.

In parallel to these formalized de jure processes there are the de facto efforts of each donor and each recipient to explore areas of common interest and commit to individual projects without reference to some over-arching 
planning process. This is particularly so, given that recipient countries are composed of many individual and institutional players, each with their own agenda. This self-organizing process is based on the fact that each donor, recipient or service provider has significant autonomy and hence would only enter into voluntary agreements based on identified mutual goals, whatever these goals might be.

What the market has taught us is that self-organizing systems require information and feedback loops. In the market, the price system is the key source of information that allows decentralized coordination, as profit-motivated suppliers and utility-motivated consumers respond in opposite ways to price movements. In the case of international development, however, it is not clear what the information structure is and what brings potential supply and demand to some balance. The lack of an appropriate information structure may lead many participants to demand more explicit coordination.

One of the major differences between centralized vs. decentralized coordination is that the former requires a pre-definition of the preferences, while in the latter preferences are revealed through the self-organizing process itself. For example, the MDGs are an example of the centralized approach that sets targets ex ante on some development goals but not others. There are MDGs for education and health, but none for better jobs for the non-poor, crime reduction or urban transport, although these issues figure prominently in the preferences of voters in many developing countries. A self-organizing system would let goals be determined by the preferences of donors and recipients, according to their own priorities and views, and the process would reveal the matches that pass muster with both parties. Just as in a market, however, the system would lack the clarity of a well-written and coherent plan.

Another difference between centralized and decentralized systems resides in the structure of the networks that they form. Centralized systems tend to be characterized by tree-like hierarchies, while decentralized systems tend to selforganize into more distributed network topologies where cycles and shortcuts between nodes in different "branches" are also prevalent and where large hubs reduce the distance between any two nodes in the system.

The purpose of this paper is threefold. First, we describe some of the features and outcomes of the emergent structure of the aid network. Second, we study, in a very indirect and imperfect way, the degree to which the system has been able to arbitrage "supply" and "demand" for international development assistance. Third, we provide a relative ranking of the degree to which aid organizations, recipient countries and development issues are effectively coordinated. Finally, the paper also pretends to be a "proof of concept" regarding the potential use of the information available through the World Wide Web to analyze complex, non-market 
activities more generally. Additionally, we have created the Aid Explorer, a web application providing information that we believe may help donors and recipients coordinate their efforts in a more decentralized and self-organizing manner. ${ }^{3}$

We do this by constructing a network that connects donor organizations, recipient countries and development issues. We analyze the degree to which this network allows countries to connect to organizations that share similar concerns, a property for which we develop a measure called Organizational Consistency. Finally, we use this to measure the degree to which organizations, countries and issues are adequately coordinated.

The study suffers from the limitations of its data source. We use the co-appearance of terms in the World Wide Web, which has been used to mine interesting associations in a number of applications, including gene and protein interactions (Cohen et al. 2005), social networks (Lee et al. 2010) and Mexican drug cartels (Coscia and Rios 2012). Words are notoriously flexible in their use, a fact that introduces noise to our data. They can also refer to negative rather than positive associations, as when an organization blames another for some bad outcome. In addition, our data does not have time resolution, meaning that we measure the connections in the data that is currently available on the web, independently of when the documents were written or published. Finally, we capture the intensity of speech, not the amount of money changing hands or the effectiveness of the projects undertaken. This implies that we cannot address issues regarding the duplication of efforts or the adequacy of the financial allocations. Also, the number of results for each query is approximate, because of optimizations made by search engines (Büttcher et al. 2010). Nevertheless, the results show that the method provides a good view of a system for which alternative empirical methodologies are not presently available.

\section{Methodology}

To analyze the state of aid coordination we study the tripartite network that connects aid organizations to each other and to recipient countries and development issues. Figure 1 depicts a representation of our methodology. We start from three distinct sets: the set of international aid organizations, the set of recipient countries and the set of development issues. For the set of organizations we include all the organizations that form part of the United Nations system, such as FAO or WHO; all the multilateral organizations including the Bretton Woods

3 http://www.atlas.cid.harvard.edu/aidxp 


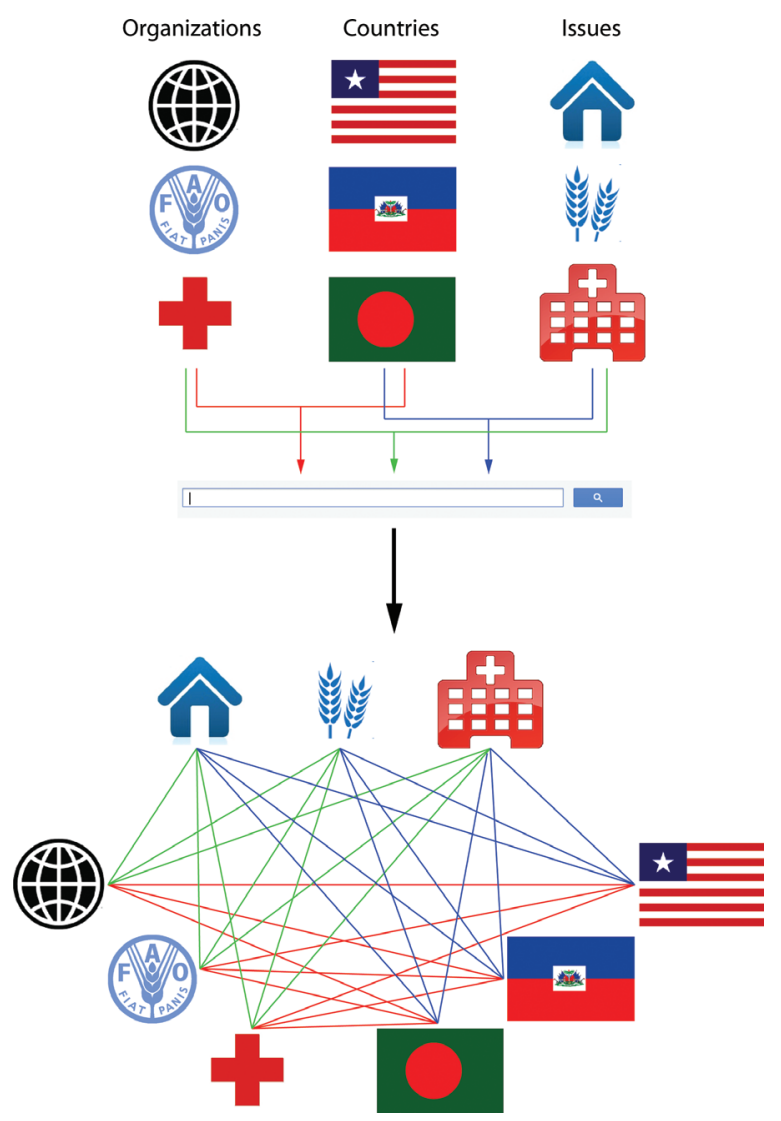

Figure 1 A Representation of our workflow. Given a set of real world entities, we classify them into "Organizations," "Countries" and "Issues." We then make couples of elements from different classes and we feed the online search engine with these queries. The results are bipartite networks connecting each country with organization and issues, each organization with countries and issue and each issue with countries and organizations.

organizations (e.g., The World Bank, the IMF, the IFC, etc.) and the regional development banks; all the bilateral organizations (i.e., development aid organizations created by single countries, such as the Belgian Technical Cooperation Agency or the Italian Development Cooperation Program). We also include a fairly comprehensive list of private foundations, such as the Bill and Melinda Gates Foundations or the Soros Foundation, but exclude those that do not have an adequate web presence, defined by a threshold on the number of pages in their website (of more than 400 pages). The final list includes 153 organizations and is presented in Table 1. 
Table 1 The List of the Organizations Included in Our Work with their Corresponding Acronym when Present.

\section{Institution}

Abu Dhabi Fund for Development

Accion International

Action Against Hunger

Acumen Fund

Adventist Development and Relief Agency

African Capacity Building Foundation

African Development Bank

Aga Khan Development Network

Agence d'Aide a la Cooperation Technique Et au Developpement

Agencia Brasileira de Cooperacao

American Friends Service Committee

American Jewish World Service

American Red Cross

American Refugee Committee

AmeriCares Disaster Relief and Humanitarian Aid Organization

Amnesty International

Andean Development Corporation

Arab Bank for Economic Development in Africa

Arab Fund for Economic \& Social Development

Ashoka

Asian Development Bank

Atlantic Philanthropies

Australian Agency for International Development

Austrian Development Agency

Austria Wirtschaftsservice Gesellschaft

Belgian Policy Plan for Development Cooperation

Belgian Technical Cooperation

Bill and Melinda Gates Foundation

Canadian International Development Agency

Caribbean Development Bank

Carlos Slim Foundation

Case Foundation

Catholic Overseas Development Agency

Childreach

China Development Bank

China Development Industrial Bank

Christian Aid

Christian Reformed World Relief Committee

Church World Service

Concern Worldwide

Congo Basin Forest Fund

Cooperative for Assistance and Relief Everywhere
Acronym

ADFD

ACCION

ADRA

ACBF-PACT

AFDB

AKDN

ACTED

$A B C$

AFSC

AJWS

ARC

AMERICARES

CAF

BADEA

ADB

AUSAID

AWSG

ACDI-CIDA

CARIBANK

CDB

CRWRC

CBF-FUND 
(Table 1 Continued)

Institution

Danish International Development Agency

Deutsche Gesellschaft fur Internationale Zusammenarbeit

Development Alternatives Inc.

Direct Relief International

Doctors Without Borders

Dubai Cares

Eurasia Foundation

EuropeAid Development and Cooperation

European Bank for Reconstruction and Development

European Investment Bank

Fast Track Initiative Catalytic Fund

Federal Ministry for Economic Cooperation and Development

Finnish Department for International Development Co-operation

Food and Agriculture Organization

Food For The Hungry

Ford Foundation

French Development Agency

German Development Bank

Global Alliance for Vaccines \& Immunization

Global Environment Facility

Global Fund to Fight Aids, Tuberculosis and Malaria

Google Org

Grameen Bank

Grameen Foundation

Hellenic Aid

Helvetas

Hewlett Foundation

High Commissioner of Human Rights

Human Rights Council

Human Rights Watch

IBM International Foundation

Instituto Portugues de Apoio ao Desenvolvimento

EBRD

EIB

BMZ

FAO

$\mathrm{FH}$

KFW.DE

OHCHR

HRW

IPAD

IADB

Inter-American Development Bank

IAF

ICRC

ICDF

IDRC

IFAD

IMF

ISDB

Islamic Development Bank

Islamic Relief Worldwide

Israel's Agency for International Development Cooperation 
(Table 1 Continued)

\begin{tabular}{|c|c|}
\hline Institution & Acronym \\
\hline \multicolumn{2}{|l|}{ Italian Development Cooperation Programme } \\
\hline Japan Bank for International Cooperation & $\mathrm{JBIC}$ \\
\hline Japan International Cooperation Agency & JICA \\
\hline Japan Official Development Assistance & JODA \\
\hline Joint United Nations Programme on HIV/AIDS & UNAIDS \\
\hline \multicolumn{2}{|l|}{ Kauffman foundation } \\
\hline Korea International Cooperation Agency & KOICA \\
\hline \multicolumn{2}{|l|}{ Lemelson Foundation } \\
\hline \multicolumn{2}{|l|}{ Liechtensteinische Entwicklungsdienst } \\
\hline \multicolumn{2}{|l|}{ Life for Relief and Development } \\
\hline Lutheran World Relief & LWR \\
\hline \multicolumn{2}{|l|}{ Lux-Development } \\
\hline \multicolumn{2}{|l|}{ MacArthur Foundation } \\
\hline \multicolumn{2}{|l|}{ Maktoum Foundation } \\
\hline \multicolumn{2}{|l|}{ Medair } \\
\hline Medical Assistance Program International & MAP \\
\hline \multicolumn{2}{|l|}{ Mercy Corps International } \\
\hline Millennium Challenge Corporation & MCC \\
\hline \multicolumn{2}{|l|}{ Mo Ibrahim Foundation } \\
\hline \multicolumn{2}{|l|}{ Multilateral Investment Guarantee Agency } \\
\hline \multicolumn{2}{|l|}{ Netherlands Ministry of Development Cooperation } \\
\hline \multicolumn{2}{|l|}{ New Zealand Agency for International Development } \\
\hline Nordic Development Fund & NDF \\
\hline North American Development Bank & NADBANK \\
\hline Norwegian Agency for Development Cooperation & NORAD \\
\hline \multicolumn{2}{|l|}{ Novartis Foundation } \\
\hline OPEC Fund for International Development & OFID \\
\hline \multicolumn{2}{|l|}{ Oxfam International } \\
\hline \multicolumn{2}{|l|}{ Poland Development Co-operation Department } \\
\hline \multicolumn{2}{|l|}{ Refugees International } \\
\hline Rockefeller Brothers Fund & RBF \\
\hline \multicolumn{2}{|l|}{ Rockefeller Foundation } \\
\hline Romania Official Development Assistance & AOD \\
\hline \multicolumn{2}{|l|}{ Salvation Army International Headquarters } \\
\hline \multicolumn{2}{|l|}{ Save the Children } \\
\hline \multicolumn{2}{|l|}{ Schwab Foundation } \\
\hline \multicolumn{2}{|l|}{ Seven fund } \\
\hline \multicolumn{2}{|l|}{ Shell Foundation } \\
\hline \multicolumn{2}{|l|}{ Skoll Foundation } \\
\hline \multicolumn{2}{|l|}{ Slovak Aid } \\
\hline Soros Foundation & \\
\hline Spanish Agency for International Cooperation & AECID \\
\hline Swedish International Development Cooperation Agency & SIDA \\
\hline
\end{tabular}


(Table 1 Continued)

\begin{tabular}{ll}
\hline Institution & Acronym \\
\hline Swiss Agency for Development and Cooperation & SDC \\
Turkish International Cooperation and Development Agency & TIKA \\
UK Department for International Development & DFID \\
United Nations Capital Development Fund & UNCDF \\
United Nations Centre for Human Settlements & \\
United Nations Conference on Trade and Development & UNCTAD \\
United Nations Democracy Fund & \\
United Nations Development Fund for Women & \\
United Nations Development Programme & UNDP \\
United Nations Educational, Scientific and Cultural Organization & UNESCO \\
United Nations Environment Programme & UNEP \\
United Nations High Commissioner for Refugees & UNHCR \\
United Nations Office for Project Services & UNOPS \\
United Nations Relief and Works Agency for Palestine Refugees & UNRWA \\
United States Agency for International Development & USAID \\
United Way International & \\
US African Development Foundation & ADF \\
Waleed bin Talal Foundation & \\
West African Development Bank & BOAD \\
World Bank & WB \\
World Concern & \\
World Food Programme & WFP \\
World Health Organization & WHO \\
World Relief & \\
World Vision International & WVI \\
\hline
\end{tabular}

We construct the set of recipient countries by focusing on those with a population above 1 million. We then rank the list of remaining countries by GDP per capita at purchasing power parity and choose the poorest 110 countries. The richest country included is Argentina and the poorest country excluded is Russia. The final list of countries is included in Table 2.

Finally, the issues are defined through a manually curated list of keywords related to development. In this context, it is crucial to choose keywords that are used only in fairly specific contexts. For example, the term "Health" is ambiguous, because it may be used in reference both to medical and financial systems. Our list of issues is based on two types of keywords: concerns and activities. Concerns relate to goals or problems, such as poverty reduction, malnutrition or civil war; while activities relate to the kind of processes that 
Table 2 The List of Countries Included in Our Work.

\begin{tabular}{|c|c|c|}
\hline Afghanistan & Guinea & Niger \\
\hline Albania & Guinea-Bissau & Nigeria \\
\hline Algeria & Haiti & Pakistan \\
\hline Angola & Honduras & Panama \\
\hline Argentina & India & Papua New Guinea \\
\hline Armenia & Indonesia & Paraguay \\
\hline Azerbaijan & Iran & Peru \\
\hline Bangladesh & Iraq & Philippines \\
\hline Belarus & Ivory Coast & Republic of Congo \\
\hline Benin & Jamaica & Romania \\
\hline Bolivia & Jordan & Rwanda \\
\hline Bosnia and Herzegovina & Kazakhstan & Senegal \\
\hline Botswana & Kenya & Serbia \\
\hline Brazil & Kosovo & Sierra Leone \\
\hline Bulgaria & Kyrgyzstan & South Africa \\
\hline Burkina Faso & Lao People Democratic & Sri Lanka \\
\hline Burundi & Republic & Sudan \\
\hline Cambodia & Latvia & Swaziland \\
\hline Cameroon & Lebanon & Syria \\
\hline Central African Republic & Lesotho & Tajikistan \\
\hline Chad & Liberia & Tanzania \\
\hline Chile & Libya & Thailand \\
\hline China & Macedonia & Timor-Leste \\
\hline Colombia & Madagascar & Togo \\
\hline Costa Rica & Malawi & Tunisia \\
\hline Democratic Republic of Congo & Malaysia & Turkey \\
\hline Dominican Republic & Mali & Turkmenistan \\
\hline Ecuador & Mauritania & Uganda \\
\hline Egypt & Mauritius & Ukraine \\
\hline El Salvador & Mexico & Uruguay \\
\hline Eritrea & Moldova & Uzbekistan \\
\hline Ethiopia & Mongolia & Venezuela \\
\hline Gabon & Morocco & Vietnam \\
\hline Gambia & Mozambique & Yemen \\
\hline Georgia & Myanmar & Zambia \\
\hline Ghana & Namibia & Zimbabwe \\
\hline Guatemala & Nepal & \\
\hline Guinea-Bissau & Nicaragua & \\
\hline
\end{tabular}

are carried out to achieve development goals, such as the banking system, the criminal justice or hospitals. Table 3 presents the list of issues, divided into concerns and activities. 
Table 3 The issues, divided into activities and concerns, included in our work.

\begin{tabular}{ll}
\hline Activities & Concerns \\
\hline Agriculture & Poverty reduction \\
Banking System & Economic growth \\
Manufacturing & Rural development \\
Housing & Climate change \\
Transportation & Environmental sustainability \\
Electricity & Job creation \\
Sanitation & Technological development \\
Primary School & Homicides \\
Hospital & Civil war \\
Tourism & Natural disaster \\
Microenterprise & Gender \\
Small and Medium Enterprise & Democracy \\
Criminal Justice & HIV/AIDS \\
Reconstruction & Refugee \\
Humanitarian Assistance & School completion \\
& Infant mortality \\
& Malnutrition \\
& Human rights \\
\hline
\end{tabular}

We gather our data through two processes. First, we build a custom search engine that indexes only the websites of the 153 aid organizations, using the Google Custom Search API. ${ }^{4}$ In this custom search engine, we are able to query either all pages or only those in the websites of the 153 aid organizations in search for documents that mention simultaneously the "World Bank" and "Medecins sans Frontiers," or the "IMF" and "Poverty Reduction," or the "African Development Bank" and Bangladesh. Acronyms and synonyms are handled by the entity recognition system of Google search engine. For the links that refer to organizations we searched the websites of the 153 aid organizations, but to study the relationship between a country and an issue we search the entire World Wide Web, and not only the websites of the aid organizations. We do this to better capture the importance of the issue for the country, beyond its salience in the aid community. As a measure of intensity of speech, we record the number of hits that contain each pair. This allows us to approximate the strength of the connection.

$4 \mathrm{https}$ //developers.google.com/custom-search/ 
We search for pairs and not triplets or quadruplets, as this would increase the number of queries beyond what is feasible to do with the use of a public API. ${ }^{5}$ For example, the set of quadruplets composed of pairs of organizations that cooperate on an issue in a country includes $86,977,440$ possible combinations $(153 \times 152 \times 110 \times 34)$, which would constitute the number of Internet queries we would need to do to map out this space. At one query per second, which is the rate allowed by a non-special Google Custom Search Engine license, this translates to nearly 3 years of uninterrupted querying. We acknowledge this to be a limitation of our approach, since aid coordination usually includes more than two organizations, working in a set of countries and a set of issues, making relationships non-dyadic. These non-dyadic relationships, however, should still be expressed imperfectly in dyadic data, since triplets, quadruplets and other sub-graphs are composed of dyads.

We begin by looking first at uni-partite networks, in which all nodes are of the same kind (connecting, for instance, countries to countries or organizations to organizations). In particular, we explore three such networks: the organization space, the issue space and the country space. In each of these, pairs of nodes are connected if both appear in the same documents with unexpectedly high frequency (defined below). Besides uni-partite networks, we also study the set of all possible bi-partite networks. A network is bi-partite when its nodes are of two different types and the links in the network connect only nodes of different type. In our case they are the Organization-Country (possible links are $153 \times 110=16,830$ ), Organization-Issue $(153 \times 34=5202)$ and Country-Issue $(110 \times 34=3740)$ networks. These three bi-partite networks involve 25,772 observations. By looking at pairs, instead of triplets or quadruplets, we keep the data collection process manageable. In total, we performed 62,140 different queries.

Figure 2 reports the frequency distribution of hits for each of the queries performed. The figures show the number of queries that delivered a certain number of hits, or in network terms, the distribution of hits of each link. Because of the heterogeneous (fat-tailed) nature of these distributions, we present them in a double logarithmic scale and bin them using a technique known as log-binning. All of the empirically observed distributions are not well described by a simple analytical distribution, such as a power-law or a log-normal distribution. Nevertheless, they vary over several orders of magnitude, indicating that the distributions are broad, or fat-tailed.

To identify the most important links, we study their statistical significance. To do this we take contrast the frequency with which each link appears in our

5 A public web API is a tool that allows programs to access web content directly. These are commonly used to build dynamic content, but can also be used to retrieve data. 

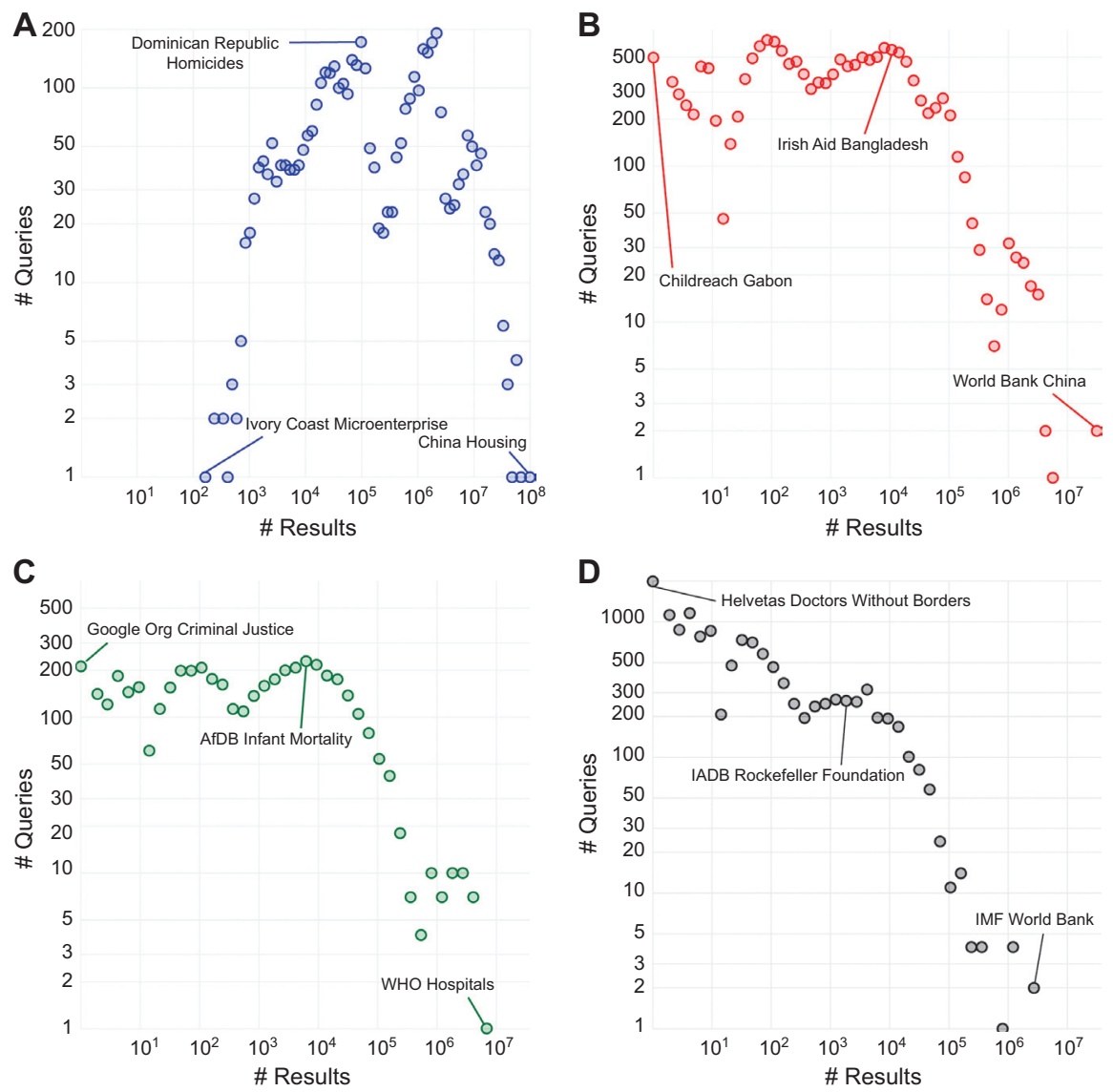

Figure 2 The distributions of our results for the different classes of queries.

(A) The distribution of results for the Country-Issue class of queries. (B) The distribution of results for the Organization-Country class of queries. (C) The distribution of results for the Organization-Issue class of queries. (D) The distribution of results for the OrganizationOrganization class of queries.

dataset and compare it with the number of times it would be expected to appear as a result of pure chance. We do this by taking the ratio between the observed and the randomly expected value, a measure called revealed comparative advantage $R$ (Balassa 1965) in international trade, relative risk in statistics (Sistrom and Garvan 2004) or lift in computer science (Geng and Hamilton 2006). Consider $N_{a, b}$ as the number of hits where organization $a$ and country $b$ appear together, $N_{a}$ as the total number of hits in which organization $a$ appears, $N_{b}$ as the total number 
of hits in which country $b$ appears and $N$ as the total number of hits in the Organization-Country queries. We define the relevance of a link between $a$ and $b R_{a, b}$ as:

$$
R_{a, b}=\frac{\frac{N_{a, b}}{N_{a}}}{\frac{N_{b}}{N}} .
$$

$R_{a, b}=1$ implies that the number of hits obtained is exactly what would be expected by pure chance. Note that $R_{a, b}$ controls for the number of total hits received by $a$ and $b$ and hence does not depend on the frequency with which different nodes appear in the data. $R_{a, b}>1$ indicates that the link is unusually frequent and $R<1$ that it is infrequent.

\section{Results}

\subsection{Country Space}

The Country Space is the network of country co-appearances in the websites of the 153 aid organizations. Figure 3 visualizes the network for $R>1.1$ rather than 1.0, to capture the links that are more significant while also making the visualization less dense and more meaningful (only 10\% of links are above 1.1). Here, the size of a node is proportional to the number of times the country is cited and its color reflects the region of the world the country belongs to. The color of the link is proportional to its relevance $R$, with green representing a stronger link and red a weaker link.

First, we observe that the space is connected, meaning that there are paths linking any two countries, despite the fact that we are only visualizing the strongest $10 \%$ of all links. This means that the aid community has not been split into unrelated clusters of countries but maintains some overall unity. Second, we observe a strong geographic effect: countries are much more likely to be connected with other countries in their same geographic region. This is particularly true in Eastern Europe, Central Asia, Sub-Saharan Africa, Middle East and North Africa and Latin America. Yet, the network also has a cluster of large countries, such as China, Brazil, India and Mexico, that concentrate a substantial number of citations and that belong to very different regions of the world.

The structure of Figure 3 is suggestive of economies of scale. Large countries can be served by many organizations, independent of their relative location because their size may justify it. Smaller countries tend to be served through geographically based clusters. 

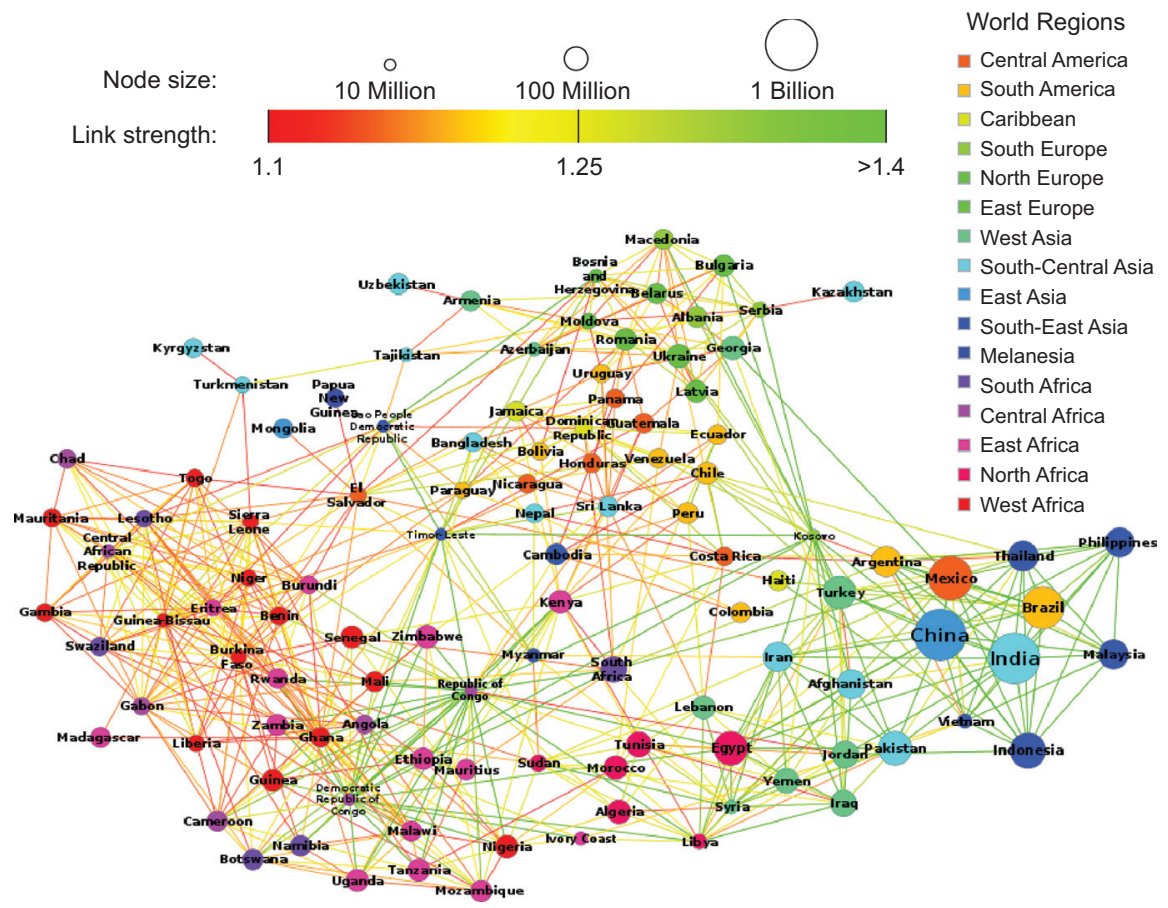

Figure 3 The Country Space, i.e., the uni-partite country network as a result of the coappearances of each couple of countries, normalized using $R$. Each node is a country, connected if $R$ was high. The color of the node is the world region where the country is located. The color of the edge is proportional to the $R$ value (green=high, orange=medium, red=low). The size of the node is the amount of documents retrieved referring to the country.

\subsection{Issue Space}

Next, we show the issue space representing all 34 concerns and activities (Figure 4) connected according to the frequency with which organizations mention both in the same document. Here we find that when we include links with $R_{I, 0}>1$ the space is not fully connected. Manufacturing, transportation, electricity and tourism are disconnected from the rest of the space, indicating that they do not tend to appear systematically together in documents discussing other issues related to economic and human development. This may reflect the fact that development thinking has tended to avoid industry-specific issues in growth strategies. Human rights, corruption and democracy form a cycle that 

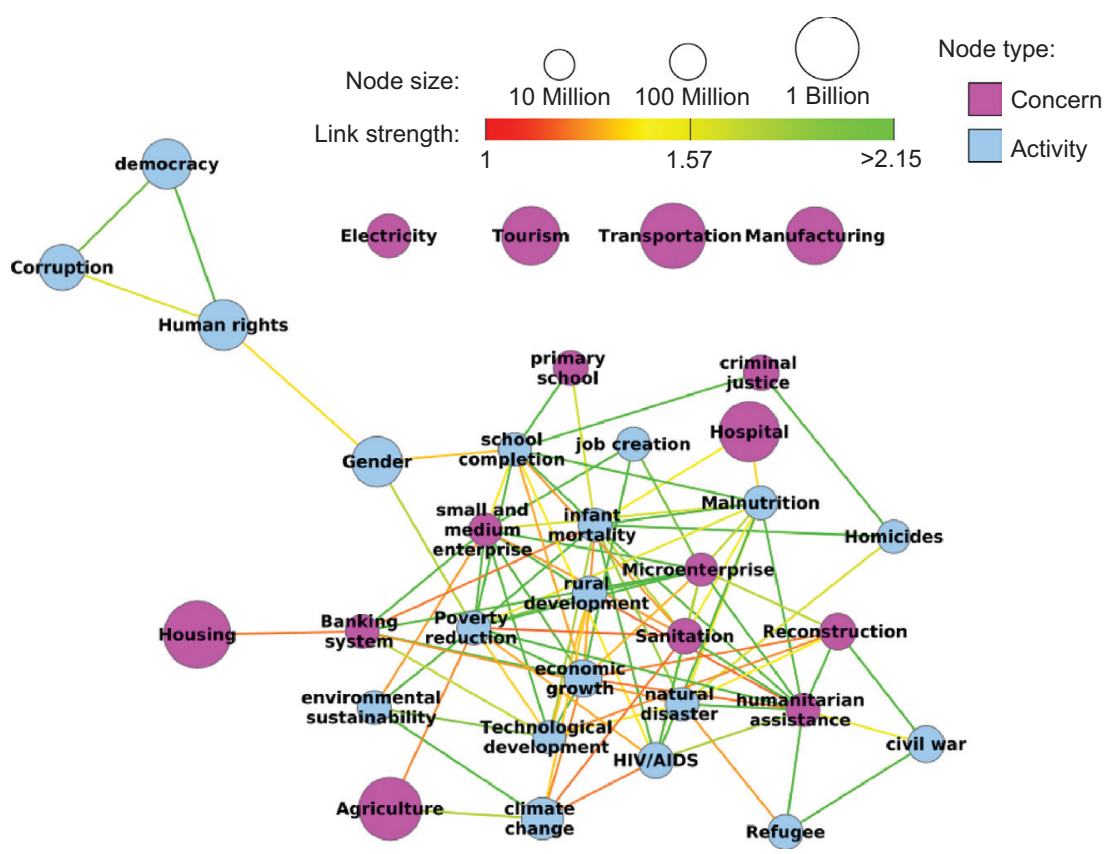

Figure 4 The Issue Space, i.e., the uni-partite Issue networks as a result of the coappearances of each couple of issues, normalized using the $R$. The nodes are the issues connected by their $R$. The color of the edge is proportional to the $R$ value (green=high, orange=medium, red=low). Node size is proportional to the popularity of the issue in the set of results considered. Node color is used to distinguish concerns (purple) from activities (blue).

is weakly connected to the rest of the space. Refugees are linked to civil war, natural disasters and humanitarian assistance. Overall, the network illustrates a sensible picture of how the international community has organized itself around issues.

\subsection{Organization Space}

Figure 5 shows the Organization Space. Since in this case the number of possible links is too large for practical visualization, we start by linking nodes through a maximum spanning tree, using Kruskal's algorithm (Kruskal 1956). The algorithm starts by connecting the two most related organizations. Then it looks for the third organization that is more strongly related to either and connects it to the 


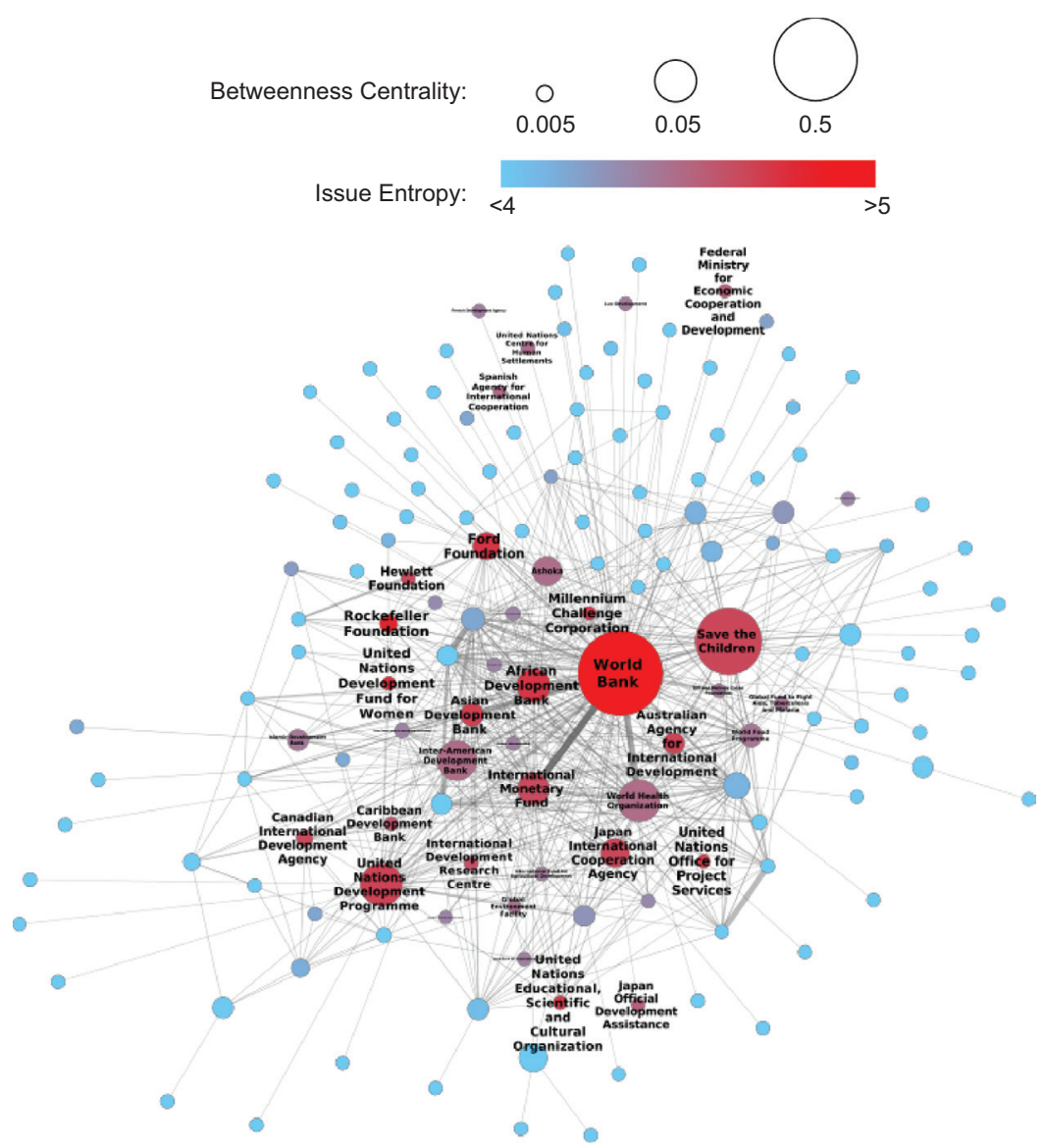

Figure 5 The Organization Space, i.e., the Organization-Organization co-occurrence network as a result of the Organization-Organization class of queries. The nodes are the aid organizations. The edges connect two aid organizations. The thickness of the edge is proportional to the number of documents in which the two organizations co-appear. The size of the node is proportional to its betweenness centrality. The color of the node is the issue entropy of the organization: red nodes are more entropic (i.e., the organization is less specialized), blue nodes are less entropic.

most related. It continues on, looking for the $n$th organization that is most related to any of the $n-1$ organizations already linked. It does so until it has linked each organization to the nearest neighbor it could find, preserving the condition that the resulting structure is a tree, meaning that there are no cycles. The resulting graph is called a tree because it connects all the organizations with the minimum 
number of possible links. We note that two of the 153 organizations, namely the Polish and the Romanian Development Agencies are not present in the network, as they are never cited together with other organizations. After constructing the maximum spanning tree, we add the strongest links so as to bring the average degree of the network to nearly 8 . This provides 453 additional links and helps illustrate the communities that exist in this network. This is the same visualization technique used to map the Product Space (Hidalgo et al. 2007) and has also been used to visualize connections in the brain (Hagmann et al. 2008).

Here, we color organizations based on how specialized they are on certain issues. To do this we use Shannon's Entropy measure (Shannon 1948):

$$
H(o)=-\sum_{i=1}^{n} p(o, i) \log _{2}(p(o, i)),
$$

where $o$ is an organization, $i$ is an issue and $p(o, i)$ is the relative frequency of issue $i$ for organization $o$, or $r_{o, i} / r_{o} . H$ should capture the fact that Human Rights Watch is more specialized than the World Bank. A high value of $H$ indicates a high level of entropy, and therefore means that the organization deals with a more diverse set of issues. In fact $2^{H}$ is equal to the effective number of issues that an organization is associated with (Jost 2006).

In Figure 5, nodes are sized according to their betweenness centrality. This is a network concept that measures the proportion of shortest paths between any two nodes that pass through a given node (Newman 2003, 2010). We interpret high betweenness centrality nodes -large nodes in our visualization - as important connectors, since these are organizations that lie in the shortest path linking many other organizations.

Figure 5 shows the effects of the broad distribution shown in Figure 2D. The space is held together by large hubs that show high betweenness centrality and high entropy. Networks with broad degree distributions can grow with very small increases in the average distance between the members of the network. This allows having an international community with a large number of organizations in which any two organizations are never too far apart. Interestingly the World Bank is the organization with the highest entropy and the most central of the nodes in the space. The second most central organization is Save the Children, which is also characterized by high entropy and centrality but connects preferentially to private donor organizations. The network exhibits a core-periphery structure where some large organizations, such as the World Bank, Save the Children, UNDP and The Ford Foundation, act as hubs and help keep the network together. We believe that it is no coincidence that the hubs have high issue entropy, since their lack of specialization is required to play a central role in the network. 
We believe that this result is significant because a common discussion among development stakeholders is the degree to which organizations should specialize. Easterly (2007), for example, argues in favor of aid organizations specializing by country or issue in order to increase efficiency. Others have argued that a clientfocused aid organization such as the World Bank, or the major regional development banks, should be able to work on the different issues that their heterogeneous developing-country partners face, and hence, must be able to deliver a more diverse suite of services. Our results suggest that, beyond this discussion, there is a systemic role played by the large, diverse organizations: they allow the network to remain connected so that the rising number of smaller, specialized entities can be linked to the rest by cooperating with the large, entropic organizations. Hence, the lack of specialization of the latter plays a systemic role. This implies that the degree of specialization of development agencies should be discussed taking into account the systemic role they play in the organization space.

\subsection{Bipartite Networks}

We now move to discuss three bipartite networks. As mentioned earlier, a bi-partite network has two kinds of nodes and the links in the network only connect nodes of different kinds. Our three bi-partite networks are the Country-Issue, Organization-Issue and Country-Organization networks. Next, we compare the structure of each bipartite network to explore the ability of the system to achieve consistency in the coordination of which organizations operate in which countries and on which issues.

Tables 4, 5 and 6 show some of the most and least connected pairs for each of the three bipartite networks. It illustrates that the method does find reasonable connections. For example, for Organization-Issue queries we see a strong relation between "Accion International" and "Microenterprise" or "Dubai Cares" and "primary school," which we expect, given the mandate of those institutions. At the same time, we see a weak connection between "Joint United Nations Programme on HIV/AIDS" and "Banking system," or between "Doctors Without Borders" and "Tourism.” The same considerations can be done for the CountryIssue queries, where we find a strong association between "Mexico" and "criminal justice," and "Malawi” and "HIV," and weak connections between "Afghanistan" and "Small and Medium Enterprises." Finally, we find a strong association between Country-Organization queries such as "Instituto Portugues de Apoio ao Desenvolvimento" and "Angola” and "North American Development Bank” and "Mexico," and a weak link between the "Aga Khan Development Network" and "Uruguay." 
Table 4 Some examples of high and low $R$ couplings of countries and issues.

\begin{tabular}{llrr}
\hline Country & Issue & Results & $\boldsymbol{R}$ \\
\hline Mexico & Criminal Justice & $7,160,000$ & 5.10753 \\
Malawi & HIV/AIDS & 820,000 & 4.74479 \\
Ecuador & Microenterprise & 8450 & 4.60329 \\
$\ldots$ & $\ldots$ & $\ldots$ & $\ldots$ \\
Syria & School Completion & 656 & 0.24633 \\
Afghanistan & SME & 2630 & 0.22421 \\
Iran & Microenterprise & 2320 & 0.18767 \\
\hline
\end{tabular}

Table 5 Some examples of high and low $R$ couplings of countries and organizations.

\begin{tabular}{llrr}
\hline Organization & Country & Results & $\boldsymbol{R}$ \\
\hline $\begin{array}{l}\text { Instituto Portugues de Apoio ao } \\
\text { Desenvolvimento }\end{array}$ & Angola & 2530 & 62.74844 \\
$\begin{array}{l}\text { Arab Bank for Economic Development } \\
\text { in Africa }\end{array}$ & Togo & 8530 & 55.40399 \\
North American Development Bank & Mexico & 5320 & 22.91313 \\
$\ldots$ & $\ldots$ & $\ldots$ & $\ldots$ \\
Aga Khan Development Network & Uruguay & 39 & 0.01914 \\
MacArthur Foundation & Bosnia and Herzegovina & 141 & 0.01385 \\
Google Org & Kazakhstan & 5 & 0.00340 \\
\hline
\end{tabular}

To study the tripartite network of organizations, countries and issues we propose to infer its properties by studying the relationship between the three possible bi-partite networks, as shown in Figure 6. Consider first the relationship between a country (e.g., Bolivia) and an issue (e.g., Microenterprise), which is captured as the bottom line of the triangle in Figure 6 and is measured by the

Table 6 Some examples of high and low $R$ couplings of issues and organizations.

\begin{tabular}{llrr}
\hline Organization & Issue & Results & $\boldsymbol{R}$ \\
\hline Accion International & Microenterprise & 2750 & 124.94252 \\
Dubai Cares & Primary School & 3980 & 46.32938 \\
Kauffman Foundation & Job Creation & 9920 & 16.35688 \\
$\ldots$ & $\ldots$ & $\ldots$ & $\ldots$ \\
Amnesty International & Microenterprise & 65 & 0.01047 \\
Joint United Nations & Banking System & 32 & 0.00410 \\
Programme on HIV/AIDS & & & \\
Doctors Without Borders & Tourism & 17 & 0.00067 \\
\hline
\end{tabular}




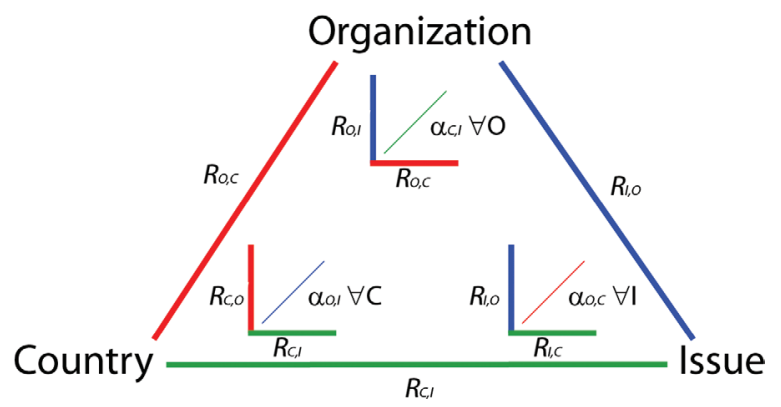

Figure 6 A representation of our tripartite structure. We do not observe directly the tripartite structure, but each of the bipartite parts (Organization-Country, Organization-Issue and Country-Issue). To have an idea about how the tripartite structure organizes itself, for each direct bipartite observation (say the Country-Issue: $R_{c, \text { }}$ ) we create an indirect observation via the other two edges, represented by a scattergram in the opposite vertex, that returns an $\alpha_{c, l}$ for the Country-Issue as the exponent of its power regression. This procedure is general for any tripartite structure observed only through its bipartite components.

associated relevance $R_{C, I}$ (equal to 4.05 in our example, as we shall see). This is the direct relationship measured by the number of documents that mention simultaneously Bolivia and Microenterprise in the World-Wide Web. Consider now the opposite vertex, meaning the top corner of the triangle. This vertex is about the relationship between the Organization-Issue and the Organization-Country networks. It shows how much the organizations that are interested in the country (e.g., Bolivia) are also interested in the issue (e.g., Microenterprise), as measured through the websites of the 153 development agencies. It is an indirect link between the country and the issue, created by looking at how the organizations relate to both.

This link is represented by a scattergram where the observations are organizations: the $\mathrm{x}$-axis captures the degree to which each organization is related to Bolivia and the y-axis measures the degree to which each organization is related to microenterprise. The relationship is summarized by the slope of the scattergram, which we call alignment and label as $\alpha_{C, I}$. In this example, $\alpha_{C, I}$ refers to the degree with which organizations that find Bolivia relevant are also interested in microenterprise.

Figure 7A-I shows the scattergrams suggested by Figure 6 for some selected cases. Figure 7A shows that organizations that are strongly (weakly) associated with Bolivia are also strongly (weakly) associated with the Microenterprise issue. For instance, the International Cooperation and Development Fund is strongly associated with both Bolivia and Microenterprise, whereas the Case Foundation is weakly associated with both Bolivia and Microenterprise. In this case we say 

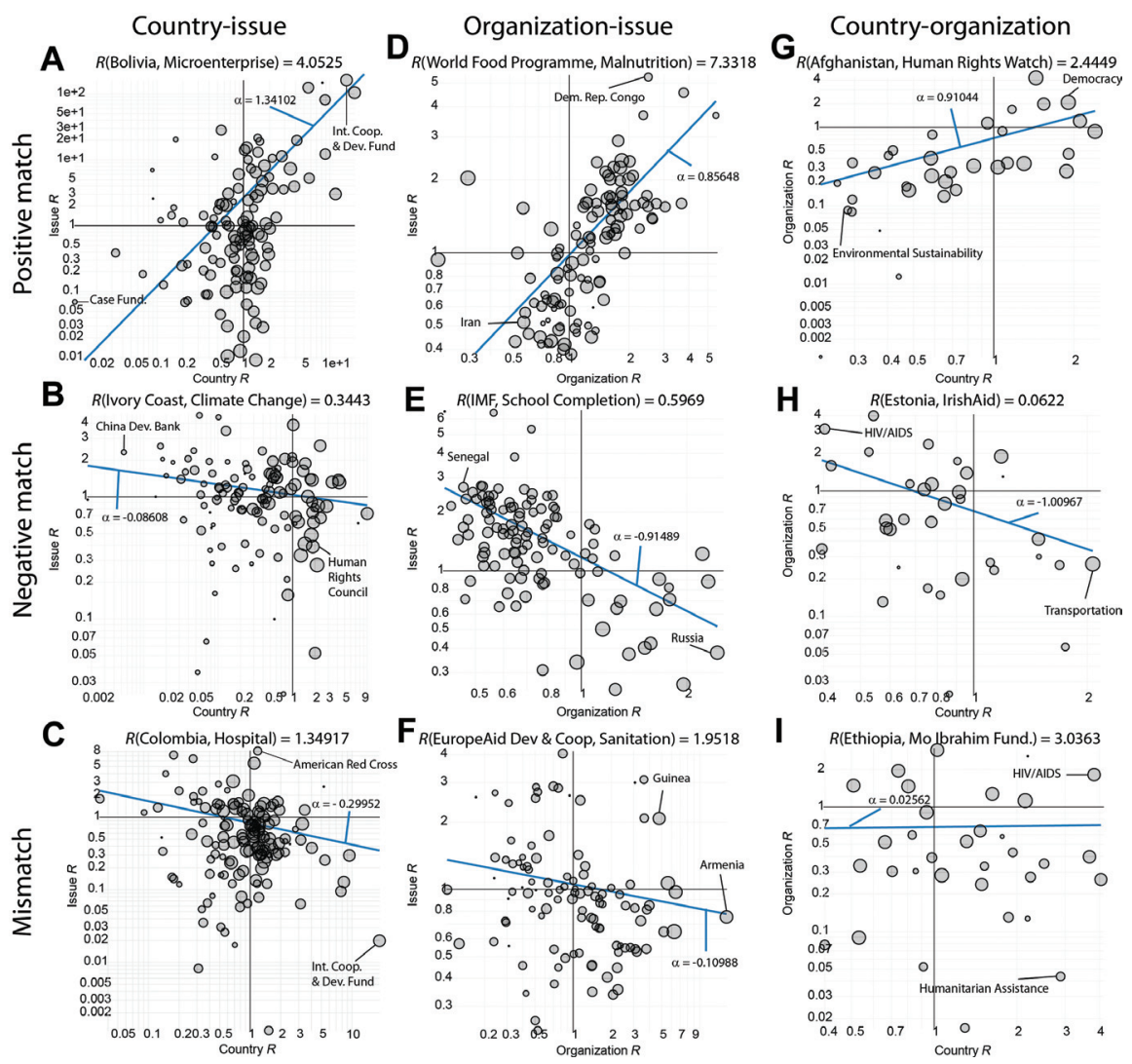

Figure 7 Scatterplots of the three bi-partite networks, showing the relationship between the two complementary measures of relevance $R$ for the Country-Issue, Organization-Issue and Organization-Country class of queries. The direct measure of relevance appears in the sub-title of the graph. The first row shows examples of combinations with high relevance $R s$ and positive alignment $\alpha$; in the second row shows examples of low Rs and negative $\alpha$; the third row shows examples of high but no significant alignment $\alpha$.

there is alignment because there is a positive association between the relevance of Bolivia and Microenterprise and this is captured by a high $\alpha_{C, I}$. The value of $R_{C, I}$ is shown at the top of each graph in Figure 7.

Figure 7A-I shows 9 scattergrams arranged in three columns. The first column shows examples from the Country-Issue bi-partite network, the second column from the Organization-Issue network and the third from the Country-Organization network. Figure 7B shows an example of a negative association: in this case between Ivory Coast and climate change. The relevance of the direct relationship is low with an $R_{C, I}=0.34$. We note that organizations associated with Ivory Coast are 
not associated with climate change, and vice versa. By contrast, the bottom graph of this first column (Figure 7C) shows what looks like an incongruity between Colombia and hospital. Colombia is strongly connected to "hospital" $\left(R_{C, I}=1.34\right)$, but the organizations that are linked to Colombia are not those that focus on health. We call this a mismatch.

The middle column in Figure 7 (D-F) studies the links between organizations and issues, and the right column, the links between organizations and countries. In both cases we show one example with a positive association (Figure 7D and G), a negative association (Figure 7E and $\mathrm{H}$ ) and a mismatch (Figure 7F and I). Given our tri-partite network, there are 25,772 possible scattergrams that can be constructed with our dataset and are available in the Aid Explorer, our web application.

\subsection{An Intermediate View of the System}

We can now look at a higher level of aggregation. We can look more systematically at the relationship between the relevance $R_{i, j}$ and the alignment $\alpha_{i, j}$ for $\mathrm{i}, \mathrm{j}=$ (Issue, Country, Organization) and $\mathrm{j} \neq \mathrm{i}$ to assess a higher order degree of consistency of the aid coordination process. When $R_{C, I}$ and $\alpha_{C, I}$ are both high it means that the country is strongly related to the issue [as shown by the high $R_{\downarrow}(C, I)$ ] but also that it is related preferentially to organizations that also focus significantly on the issue. We say that there is a positive match between relevance as captured by $R_{C, I}$ and the alignment as captured by $\alpha_{C, I}$. We call this relationship the issueconsistency of the country.

Figure 8A represents the issue-consistency of Bolivia as it illustrates the relationship between relevance $R_{C, I}$ and alignment $\alpha_{C, I}$ for all issues and not just for microenterprise. Here, the y-axis is the relevance of the issue to Bolivia, measured by searching the whole World Wide Web. The x-axis measures the alignment $\alpha_{C, I}$ between Bolivia and each issue through the consistency with which the organizations that are linked to Bolivia also find the issue salient, measured through the websites of aid organizations. For example, Figure 7A showed that the organizations associated with Bolivia are also associated with Microenterprise. Hence, in Figure 8A, microenterprise appears as a single point in the upper-right quadrant (high $R_{C, I}$ and $\alpha_{C, I}$ ). Conversely, Bolivia is not strongly associated with "Refugee" $\left(R_{C, I}<1\right)$ and in this case the alignment of organizations associated with both Refugees and Bolivia is poor, with a negative $\alpha_{C, I}$. Overall, the Bolivia Issue Plot (Figure 8A) shows a high issue consistency of Bolivia, given that issues that are strongly associated with Bolivia (high $R_{C, I}$ ) are also the issues where there is a positive alignment.

Figure $8 \mathrm{~A}$ uses the relationship between the bottom of the triangle in Figure 6 and the top vertex. But we could also create a similar relationship using the left 

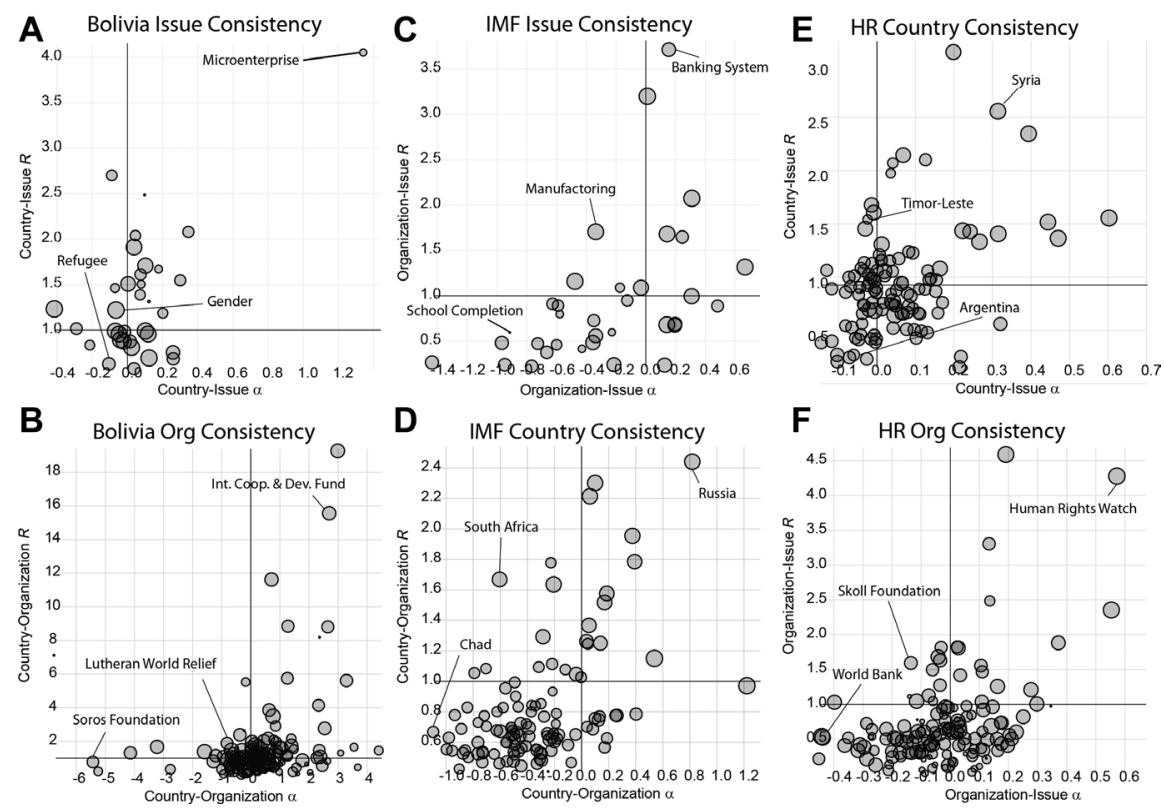

Figure 8 Consistency graphs: the scattergrams show relevance vs. alignment scatterplots for the three bi-partite plots and two consistency criteria. Given a country we plot the relationship between its issue relevance and the alignment $\alpha$ of organizations with both the country and the issues. We repeat the same procedure also for organizations and issues using each of the two related concepts of alignment.

side of the triangle and the right-side vertex. This means that we would relate the relevance of the Organization-Country link $R_{O, C}$ to the alignment between organization and country $a_{O, C}$, for a particular country, say Bolivia. This is shown in Figure 8B. Here the points on the scattergram are organizations rather than issues and it tells us which are the organizations that are salient to Bolivia and aligned with its issues. We refer to the relationship in Figure 8A as a country's issue consistency, while that of Figure 8B as a country's organizational consistency.

Figure $8 \mathrm{C}$ illustrates the issue consistency of organizations, using the IMF as an example. It is based on relating the right side with the left vertex of Figure 6. It shows which are the issues that are relevant to the IMF and that are aligned with it in terms of being important for the countries that the IMF cites more frequently. Figure 8D shows the country consistency of the IMF. It describes what are the countries that are relevant for the IMF and how aligned are the issues in those countries with those that the IMF focuses on. It is based on the left side and the right vertex of Figure 6.

Figure $8 \mathrm{E}$ looks at human rights as an example of the country consistency of issues. It is based on relating the bottom side to the top vertex of Figure 6. It 
shows that Human Rights is a relevant issue in Syria and that the organizations that care about human rights also care about Syria, but it is a less salient issue in Argentina and so the organizations that care about human rights are less salient there. Figure 8F shows the organization consistency of issues. It is based on relating the right side to the left vertex of Figure 6. It shows that human rights are a salient issue for Human Rights Watch and that the organization focuses on countries where the human rights issue is salient. The opposite is true about the World Bank. By contrast, the Skoll Foundation finds the human rights issue relevant, but it does not align well with countries where the issue is salient and hence shows a negative alignment.

These sets of graphs can allow us to understand the aspects that make a country, an organization or an issue be more or less consistent. Given that there are three nodes and two types of consistency, we can generate $2 \times 110=220$ country graphs, $2 \times 153=306$ organization graphs and $2 \times 34=68$ issue graphs, for a total of 594 graphs. This is a more aggregated view of the system than the 25,772 graphs of the kind shown in Figure 7, and can permit an analysis at a more systemic level, but it still is a very high dimensional description.

\subsection{An Aggregate View of the Aid Coordination Network}

To develop a more systemic view of the consistency of the aid coordination network we can re-aggregate the data to a higher level. Here, we look for a measure that tells us to what extent countries are being engaged by the right organizations, given the issues that are salient to them. Or alternatively, which organizations are engaged with the right countries, given the issues that they have decided to focus on. Or which are the issues that have an appropriate deployment of organizations in countries.

To make this judgment we propose to develop three overall consistency indexes, one for each node type in the tri-partite network. The index would be the proportion of the relevant links $R_{i, j}>1$ that also have a consistency $\alpha_{i, j}>\xi$ where $\xi$ is some cutoff value. ${ }^{6}$ To make the indexes meaningful and comparable, we normalize them by the maximum number that the ratio could achieve on average for all

\footnotetext{
6 An alternative would be to consider a weighted measure, such as a correlation, rather than one based on cutoffs and counts. We did not take this route because we care about the quality of positive matches rather than the intensity of the negative matches. A regression approach treats both as symmetric. Secondly, correlation-based measures give higher weights to both positive and negative outliers and given the noise in the data, make the results less precise. This issue could be revisited if data based on triplets rather than pairs were used, as discussed in the concluding section.
} 
the observations in the set if consistency was perfect. More precisely we propose to measure the following overall consistency indexes:

$$
\kappa_{i, s}=\frac{\frac{N\left(\alpha_{i, j, S}>\xi \bigcap R_{i, j, S}>1\right)}{N\left(R_{i, j, S}>1\right)}}{\frac{N\left(\alpha_{i, j, S \forall j}>\xi\right)}{N\left(R_{i, j, S \forall j}>1\right)}}
$$

where the letter $S$ refers to the set to which the elements belong, $i=$ countries, organizations or issues. The index $i$ refers to the specific country, issue or organization that is being considered and the $j$ 's depend on the type of consistency that is considered. For the case of organizations, we use the country-consistency, as this will tell us, given the part of the world that the organization has chosen to focus on, whether it is in tune with the issues that are salient in those countries. We measure the degree to which the countries that the organization cares about, meaning that $R_{O, C}>1$, are countries where the issues the organization cares about are also salient in the country, and hence have significant alignment $\alpha_{0, C}>\xi$.

For the case of countries we use their issue consistency, since we care that the issues that a country confronts be adequately tended to, independently of which organization does it. For issues we use the organization consistency, given that we want to assess the degree to which organizations are adequately deployed to deal with the issue that countries find salient.

In general, the number of total observations with $\alpha_{i, j}>\xi$ will depend on the choice of $\xi$. To make our measure less dependent on this choice, we normalize the numerator dividing it by the ratio between the total number observations with $\alpha_{i, j}>\xi$ and the number of observations with $R_{i, j}>1$. This latter ratio is the highest possible value that perfect consistency would achieve, on average. This normalization factor makes a ratio of 1 for the whole class to imply perfect consistency.

To decide on the cutoffs, we note that out of 3740 observations in our Country-Issue network, 1768 have $R_{C, I}>1(47.3 \%)$ and 916 have a $\alpha_{C, I}>0.2$. This means that if the system were perfectly coordinated we would get a ratio of $51.8 \%$ of the observations with $R_{C, I}>1$ that also have $\alpha_{C, I}>0.2$. (see Table 7). So, by dividing by this ratio, we measure consistency relative to this maximum. This approach corrects for the arbitrariness of the cutoff and for noise in our data. We use the same cutoff of 0.2 for the organization-issue network and a cutoff of 0.5 for the Country-Organization network. The relevant numbers are shown in Table 7.

This measure allows us to get a sense of the degree to which each country, each organization and each issue is adequately coordinated. Tables 8, 9 and 10 show rankings based on our overall consistency measure. 
Table 7 Summary statistics on salience and consistency.

\begin{tabular}{|c|c|c|c|c|c|c|}
\hline & (a) & (b) & $(c)=(b) /(a)$ & (d) & (e) & $(f)=(e) /(b)$ \\
\hline Bipartite Networks & N & $N(R>1)$ & Ratio & Cutoff & $N$ (a>cutoff) & $N(a) / N(R)$ \\
\hline Country, Issue & 3740 & 1768 & $47.3 \%$ & 0.2 & 916 & $51.8 \%$ \\
\hline Organization, Issue & 5202 & 1889 & $36.3 \%$ & 0.2 & 914 & $48.4 \%$ \\
\hline Organization, Country & 16,830 & 6890 & $40.9 \%$ & 0.5 & 5206 & $75.6 \%$ \\
\hline
\end{tabular}

Table 8 shows the ranking of aid organizations according to our overall consistency index. Note that this measure considers the countries that the organization finds salient, so it should not penalize regionally focused institutions. It then asks whether the organization engages countries in issues that are salient to them. The top of the list is dominated by bilateral development agencies such as those of China, Norway, Portugal and Austria. However, this is not a general

Table 8 The organization ranking. For each organization we report the degree to which the countries that are relevant for the organization also exhibit high issue alignment. The number reflects the percentage consistency relative to the theoretical maximum for the average of the whole table (see in the text and Table 7).

\begin{tabular}{rlr}
\hline Rank & Organization & Country consistency \\
\hline 1 & China Development Industrial Bank & $132.35 \%$ \\
2 & Childreach & $132.35 \%$ \\
3 & Norwegian Agency for Development Cooperation & $127.25 \%$ \\
4 & Andean Development Corporation & $117.64 \%$ \\
5 & Arab Bank for Economic Development in Africa & $117.22 \%$ \\
6 & Cooperative for Assistance and Relief Everywhere & $117.00 \%$ \\
7 & Fast Track Initiative Catalytic Fund & $116.06 \%$ \\
8 & Instituto Portugues de Apoio ao Desenvolvimento & $115.80 \%$ \\
9 & Austrian Development Agency & $115.27 \%$ \\
10 & International Cooperation and Development Fund & $111.45 \%$ \\
11 & Austria Wirtschaftsservice Gesellschaft & $109.24 \%$ \\
12 & West African Development Bank & $108.99 \%$ \\
13 & New Zealand Agency for International Development & $108.86 \%$ \\
14 & German Development Bank & $108.86 \%$ \\
15 & Korea International Cooperation Agency & $108.28 \%$ \\
16 & African Capacity Building Foundation & $107.53 \%$ \\
17 & United Nations Capital Development Fund & $106.22 \%$ \\
18 & UK Department for International Development & $105.88 \%$ \\
19 & Belgian Technical Cooperation & $105.20 \%$ \\
20 & EuropeAid Development and Cooperation & $103.99 \%$
\end{tabular}


(Table 8 Continued)

\begin{tabular}{|c|c|c|}
\hline Rank & Organization & Country consistency \\
\hline 21 & OPEC Fund for International Development & $103.80 \%$ \\
\hline 22 & Nordic Development Fund & $103.73 \%$ \\
\hline 23 & US African Development Foundation & $102.94 \%$ \\
\hline 24 & Spanish Agency for International Cooperation & $102.74 \%$ \\
\hline 25 & Japan Bank for International Cooperation & $101.80 \%$ \\
\hline 26 & Adventist development and relief agency & $100.26 \%$ \\
\hline 27 & Christian Reformed World Relief Committee & $99.77 \%$ \\
\hline 28 & United States Agency for International Development & $99.67 \%$ \\
\hline 29 & Swedish International Development Cooperation Agency & $99.26 \%$ \\
\hline 30 & Congo Basin Forest Fund & $98.70 \%$ \\
\hline 31 & Japan Official Development Assistance & $95.58 \%$ \\
\hline 32 & Mercy Corps International & $95.06 \%$ \\
\hline 33 & Accion International & $93.92 \%$ \\
\hline 34 & United Way International & $93.66 \%$ \\
\hline 35 & Canadian International Development Agency & $91.62 \%$ \\
\hline 36 & Global Alliance for Vaccines \& Immunization & $90.99 \%$ \\
\hline 37 & Agencia Brasileira de Cooperacao & $90.55 \%$ \\
\hline 38 & Development Alternatives Inc. & $90.38 \%$ \\
\hline 39 & International Fund for Agricultural Development & $89.29 \%$ \\
\hline 40 & Medical Assistance Program International & $88.23 \%$ \\
\hline 41 & Italian Development Cooperation Programme & $86.63 \%$ \\
\hline 42 & Hellenic Aid & $84.90 \%$ \\
\hline 43 & Grameen Foundation & $84.84 \%$ \\
\hline 44 & Israel's Agency for International Development Cooperation & $84.22 \%$ \\
\hline 45 & American Refugee Committee & $83.33 \%$ \\
\hline 46 & Asian Development Bank & $80.88 \%$ \\
\hline 47 & United Nations Development Programme & $79.41 \%$ \\
\hline 48 & Case Foundation & $79.41 \%$ \\
\hline 49 & Inter-American Foundation & $78.20 \%$ \\
\hline 50 & Acumen Fund & $76.85 \%$ \\
\hline 51 & Islamic Relief Worldwide & $76.62 \%$ \\
\hline 52 & Lux-Development & $76.10 \%$ \\
\hline 53 & Food For The Hungry & $75.00 \%$ \\
\hline 54 & United Nations Relief and Works Agency for Palestine Refugees & $74.24 \%$ \\
\hline 55 & French Development Agency & $73.53 \%$ \\
\hline 56 & AmeriCares Disaster Relief and Humanitarian Aid Organization & $73.53 \%$ \\
\hline 57 & Swiss Agency for Development and Cooperation & $72.70 \%$ \\
\hline 58 & Slovak Aid & $71.84 \%$ \\
\hline 59 & Aga Khan Development Network & $70.58 \%$ \\
\hline 60 & Global Fund to Fight Aids, Tuberculosis and Malaria & $68.01 \%$ \\
\hline 61 & Japan International Cooperation Agency & $67.58 \%$ \\
\hline 62 & World Concern & $66.17 \%$ \\
\hline 63 & Novartis Foundation & $66.17 \%$ \\
\hline 64 & World Vision International & $65.29 \%$ \\
\hline
\end{tabular}


(Table 8 Continued)

\begin{tabular}{|c|c|c|}
\hline Rank & Organization & Country consistency \\
\hline 65 & Global Environment Facility & $64.63 \%$ \\
\hline 66 & Life for Relief and Development & $63.89 \%$ \\
\hline 67 & American Red Cross & $63.89 \%$ \\
\hline 68 & Danish International Development Agency & $62.04 \%$ \\
\hline 69 & Multilateral Investment Guarantee Agency & $61.64 \%$ \\
\hline 70 & Church World Service & $61.33 \%$ \\
\hline 71 & United Nations Centre for Human Settlements & $61.23 \%$ \\
\hline 72 & Irish Aid & $60.56 \%$ \\
\hline 73 & World Food Programme & $59.39 \%$ \\
\hline 74 & United Nations Development Fund for Women & $58.82 \%$ \\
\hline 75 & Medair & $58.82 \%$ \\
\hline 76 & American Jewish World Service & $58.39 \%$ \\
\hline 77 & Australian Agency for International Development & $55.50 \%$ \\
\hline 78 & Shell Foundation & $54.50 \%$ \\
\hline 79 & Schwab Foundation & $54.50 \%$ \\
\hline 80 & Lemelson Foundation & $53.92 \%$ \\
\hline 81 & Caribbean Development Bank & $53.77 \%$ \\
\hline 82 & Atlantic Philanthropies & $52.94 \%$ \\
\hline 83 & North American Development Bank & $50.90 \%$ \\
\hline 84 & Netherlands Ministry of Development Cooperation & $50.60 \%$ \\
\hline 85 & European Investment Bank & $49.94 \%$ \\
\hline 86 & Lutheran World Relief & $49.16 \%$ \\
\hline 87 & Joint United Nations Programme on HIV/AIDS & $48.76 \%$ \\
\hline 88 & African Development Bank & $48.53 \%$ \\
\hline 89 & IBM International Foundation & $47.27 \%$ \\
\hline 90 & Dubai Cares & $46.32 \%$ \\
\hline 91 & Rockefeller Brothers Fund & $46.03 \%$ \\
\hline 92 & Carlos Slim Foundation & $44.12 \%$ \\
\hline 93 & Refugees International & $43.53 \%$ \\
\hline 94 & Helvetas & $41.79 \%$ \\
\hline 95 & United Nations High Commissioner for Refugees & $41.72 \%$ \\
\hline 96 & World Relief & $41.66 \%$ \\
\hline 97 & Arab Fund for Economic \& Social Development & $39.70 \%$ \\
\hline 98 & Amnesty International & $39.70 \%$ \\
\hline 99 & International Committee of the Red Cross & $39.21 \%$ \\
\hline 100 & Food and Agriculture Organization & $39.16 \%$ \\
\hline 101 & Catholic Overseas Development Agency & $38.50 \%$ \\
\hline 102 & High Commissioner of Human Rights & $38.47 \%$ \\
\hline 103 & Seven fund & $37.81 \%$ \\
\hline 104 & Direct Relief International & $37.81 \%$ \\
\hline 105 & Oxfam International & $37.53 \%$ \\
\hline 106 & American Friends Service Committee & $37.22 \%$ \\
\hline 107 & China Development Bank & $36.76 \%$ \\
\hline 108 & United Nations Environment Programme & $36.61 \%$ \\
\hline
\end{tabular}


(Table 8 Continued)

\begin{tabular}{|c|c|c|}
\hline Rank & Organization & Country consistency \\
\hline 109 & International Development Research Centre & $34.83 \%$ \\
\hline 110 & Eurasia Foundation & $34.83 \%$ \\
\hline 111 & Human Rights Watch & $34.66 \%$ \\
\hline 112 & Millennium Challenge Corporation & $34.61 \%$ \\
\hline 113 & United Nations Office for Project Services & $34.41 \%$ \\
\hline 114 & Bill and Melinda Gates Foundation & $33.61 \%$ \\
\hline 115 & Deutsche Gesellschaft fur Internationale Zusammenarbeit & $32.28 \%$ \\
\hline 116 & Concern Worldwide & $30.08 \%$ \\
\hline 117 & Inter-American Development Bank & $29.88 \%$ \\
\hline 118 & Skoll Foundation & $29.41 \%$ \\
\hline 119 & Mo Ibrahim Foundation & $29.05 \%$ \\
\hline 120 & Human Rights Council & $28.95 \%$ \\
\hline 121 & Grameen Bank & $28.77 \%$ \\
\hline 122 & Waleed bin Talal Foundation & $22.06 \%$ \\
\hline 123 & Turkish International Cooperation and Development Agency & $21.61 \%$ \\
\hline 124 & Action Against Hunger & $21.61 \%$ \\
\hline 125 & United Nations Conference on Trade and Development & $21.10 \%$ \\
\hline 126 & Soros Foundation & $20.05 \%$ \\
\hline 127 & European Bank for Reconstruction and Development & $20.05 \%$ \\
\hline 128 & Agence d'Aide a la Cooperation Technique Et au Developpement & $17.08 \%$ \\
\hline 129 & MacArthur Foundation & $16.54 \%$ \\
\hline 130 & Google Org & $16.54 \%$ \\
\hline 131 & Federal Ministry for Economic Cooperation and Development & $16.54 \%$ \\
\hline 132 & Doctors Without Borders & $16.29 \%$ \\
\hline 133 & Abu Dhabi Fund for Development & $13.57 \%$ \\
\hline 134 & World Health Organization & $13.23 \%$ \\
\hline 135 & United Nations Democracy Fund & $12.22 \%$ \\
\hline 136 & United Nations Educational, Scientific and Cultural Organization & $12.17 \%$ \\
\hline 137 & International Monetary Fund & $11.51 \%$ \\
\hline 138 & Finnish Department for International Development Co-operation & $11.03 \%$ \\
\hline 139 & Christian Aid & $10.18 \%$ \\
\hline 140 & Save the Children & $9.57 \%$ \\
\hline 141 & Salvation Army International Headquarters & $9.45 \%$ \\
\hline 142 & Maktoum Foundation & $8.82 \%$ \\
\hline 143 & Ashoka & $5.29 \%$ \\
\hline 144 & Liechtensteinische Entwicklungsdienst & $5.09 \%$ \\
\hline 145 & Kauffman foundation & $4.01 \%$ \\
\hline 146 & Hewlett Foundation & $2.94 \%$ \\
\hline 147 & Rockefeller Foundation & $2.45 \%$ \\
\hline 148 & Ford Foundation & $1.59 \%$ \\
\hline 149 & World Bank & $0.00 \%$ \\
\hline 150 & Islamic Development Bank & $0.00 \%$ \\
\hline 151 & Belgian Policy Plan for Development Cooperation & $0.00 \%$ \\
\hline
\end{tabular}


Table 9 The country ranking. For each country we report the degree to which the issues that are relevant for the country also exhibit high organizational alignment. The number reflects the percentage consistency relative to the theoretical maximum for the average of the whole table (see in the text and Table 7).

\begin{tabular}{|c|c|c|}
\hline Rank & Country & Issue consistency \\
\hline 1 & El Salvador & $124.89 \%$ \\
\hline 2 & Iraq & $122.83 \%$ \\
\hline 3 & Mauritius & $120.63 \%$ \\
\hline 4 & Chile & $115.81 \%$ \\
\hline 5 & Iran & $107.23 \%$ \\
\hline 6 & Liberia & $105.28 \%$ \\
\hline 7 & Syria & $96.51 \%$ \\
\hline 8 & Panama & $96.51 \%$ \\
\hline 9 & Pakistan & $96.51 \%$ \\
\hline 10 & Afghanistan & $96.51 \%$ \\
\hline 11 & Gambia & $91.43 \%$ \\
\hline 12 & Benin & $91.43 \%$ \\
\hline 13 & Bosnia and Herzegovina & $90.07 \%$ \\
\hline 14 & Serbia & $87.73 \%$ \\
\hline 15 & Albania & $87.73 \%$ \\
\hline 16 & Cameroon & $86.86 \%$ \\
\hline 17 & Tunisia & $85.78 \%$ \\
\hline 18 & Macedonia & $85.78 \%$ \\
\hline 19 & Jamaica & $85.78 \%$ \\
\hline 20 & Ecuador & $85.78 \%$ \\
\hline 21 & Mauritania & $84.44 \%$ \\
\hline 22 & Sri Lanka & $82.72 \%$ \\
\hline 23 & Niger & $82.72 \%$ \\
\hline 24 & Sierra Leone & $81.27 \%$ \\
\hline 25 & Mexico & $80.42 \%$ \\
\hline 26 & Argentina & $80.42 \%$ \\
\hline 27 & Papua New Guinea & $79.48 \%$ \\
\hline 28 & Myanmar & $78.96 \%$ \\
\hline 29 & Lebanon & $77.21 \%$ \\
\hline 30 & Jordan & $77.21 \%$ \\
\hline 31 & Honduras & $77.21 \%$ \\
\hline 32 & Botswana & $77.21 \%$ \\
\hline 33 & Ghana & $75.06 \%$ \\
\hline 34 & Guinea-Bissau & $74.24 \%$ \\
\hline 35 & Costa Rica & $74.24 \%$ \\
\hline 36 & Zambia & $73.53 \%$ \\
\hline 37 & Nicaragua & $73.53 \%$ \\
\hline 38 & Yemen & $72.38 \%$ \\
\hline 39 & Romania & $72.38 \%$ \\
\hline 40 & Uruguay & $71.11 \%$ \\
\hline
\end{tabular}


(Table 9 Continued)

\begin{tabular}{|c|c|c|}
\hline Rank & Country & Issue consistency \\
\hline 41 & Paraguay & $71.11 \%$ \\
\hline 42 & Armenia & $71.11 \%$ \\
\hline 43 & Dominican Republic & $70.19 \%$ \\
\hline 44 & Ukraine & $68.93 \%$ \\
\hline 45 & Ivory Coast & $68.93 \%$ \\
\hline 46 & Kazakhstan & $68.12 \%$ \\
\hline 47 & Gabon & $68.12 \%$ \\
\hline 48 & Chad & $68.12 \%$ \\
\hline 49 & Azerbaijan & $68.12 \%$ \\
\hline 50 & Republic of Congo & $67.13 \%$ \\
\hline 51 & Peru & $64.34 \%$ \\
\hline 52 & Namibia & $64.34 \%$ \\
\hline 53 & Mozambique & $64.34 \%$ \\
\hline 54 & Morocco & $64.34 \%$ \\
\hline 55 & Mali & $64.34 \%$ \\
\hline 56 & Lao People Democratic Republic & $64.34 \%$ \\
\hline 57 & Haiti & $64.34 \%$ \\
\hline 58 & Colombia & $64.34 \%$ \\
\hline 59 & Burkina Faso & $64.34 \%$ \\
\hline 60 & Algeria & $64.34 \%$ \\
\hline 61 & Senegal & $61.41 \%$ \\
\hline 62 & Togo & $60.95 \%$ \\
\hline 63 & Tajikistan & $60.32 \%$ \\
\hline 64 & Malawi & $58.74 \%$ \\
\hline 65 & Latvia & $57.90 \%$ \\
\hline 66 & Cambodia & $57.90 \%$ \\
\hline 67 & Bulgaria & $57.90 \%$ \\
\hline 68 & Madagascar & $56.77 \%$ \\
\hline 69 & Central African Republic & $56.77 \%$ \\
\hline 70 & Guinea & $56.30 \%$ \\
\hline 71 & Libya & $55.15 \%$ \\
\hline 72 & Ethiopia & $55.15 \%$ \\
\hline 73 & China & $55.15 \%$ \\
\hline 74 & Brazil & $55.15 \%$ \\
\hline 75 & Democratic Republic of Congo & $54.04 \%$ \\
\hline 76 & Guatemala & $53.61 \%$ \\
\hline 77 & Nepal & $50.79 \%$ \\
\hline 78 & Zimbabwe & $48.25 \%$ \\
\hline 79 & Swaziland & $48.25 \%$ \\
\hline 80 & Philippines & $48.25 \%$ \\
\hline 81 & Eritrea & $48.25 \%$ \\
\hline 82 & Timor-Leste & $46.32 \%$ \\
\hline 83 & Nigeria & $45.41 \%$ \\
\hline 84 & India & $45.41 \%$ \\
\hline
\end{tabular}


(Table 9 Continued)

\begin{tabular}{rlr}
\hline Rank & Country & Issue consistency \\
\hline 85 & Angola & $45.41 \%$ \\
86 & Moldova & $44.54 \%$ \\
87 & Bangladesh & $43.87 \%$ \\
88 & Venezuela & $42.89 \%$ \\
89 & Uganda & $42.89 \%$ \\
90 & Sudan & $42.89 \%$ \\
91 & Lesotho & $40.63 \%$ \\
92 & Bolivia & $40.63 \%$ \\
93 & Kosovo & $35.09 \%$ \\
94 & Burundi & $35.09 \%$ \\
95 & Turkmenistan & $29.69 \%$ \\
96 & South Africa & $28.95 \%$ \\
97 & Rwanda & $28.95 \%$ \\
98 & Malaysia & $27.57 \%$ \\
99 & Kenya & $27.57 \%$ \\
100 & Egypt & $27.57 \%$ \\
101 & Uzbekistan & $24.13 \%$ \\
102 & Kyrgyzstan & $24.13 \%$ \\
103 & Belarus & $24.13 \%$ \\
104 & Tanzania & $19.30 \%$ \\
105 & Georgia & $17.55 \%$ \\
106 & Indonesia & $14.85 \%$ \\
107 & Vietnam & $12.87 \%$ \\
108 & Turkey & $0.00 \%$ \\
109 & Thailand & $0.00 \%$ \\
110 & Mongolia & $0.00 \%$ \\
\hline & & \\
\hline
\end{tabular}

feature of bilateral agencies as those of Belgium, Finland and Abu Dhabi are at the bottom of the list. At the top of the list we do find some multilateral development agencies such as the Arab Bank for Economic Development in Africa and the Andean Development Corporation, although the Islamic Development Bank is at the bottom of the list. But the large central hubs such as the World Bank, the IMF and Save the Children are at the bottom of the list. This may be due to their high entropy, as they deal with many countries and issues, given the systemic role we have argued they perform.

We find many private foundations at the bottom of the list, such as the Ford, Rockefeller, Hewlett, Kauffman, and Google Foundations. This may be due to the fact that these organizations are not necessarily focused on typical development issues. Some as in the case of the Soros Foundation, tend to take a contrarian 
Table 10 The issue ranking. For each organization we report the degree to which the issues that are relevant for countries also exhibit high organizational alignment. The number reflects the percentage consistency relative to the theoretical maximum for the average of the whole table (see in the text and Table 7).

\begin{tabular}{rlr}
\hline Rank & Issue & Organization Consistency \\
\hline 1 & Malnutrition & $129.16 \%$ \\
2 & School completion & $127.75 \%$ \\
3 & Poverty reduction & $127.39 \%$ \\
4 & Humanitarian assistance & $125.47 \%$ \\
5 & HIV/AIDS & $125.01 \%$ \\
6 & Environmental sustainability & $118.09 \%$ \\
7 & Infant mortality & $114.40 \%$ \\
8 & Microenterprise & $112.39 \%$ \\
9 & Homicides & $103.33 \%$ \\
10 & Small and medium enterprise & $101.69 \%$ \\
11 & Refugee & $99.50 \%$ \\
12 & Sanitation & $99.19 \%$ \\
13 & Natural disaster & $93.58 \%$ \\
14 & Rural development & $85.51 \%$ \\
15 & Criminal justice & $79.01 \%$ \\
16 & Primary school & $55.76 \%$ \\
17 & Technological development & $46.50 \%$ \\
18 & Gender & $40.82 \%$ \\
19 & Human rights & $39.74 \%$ \\
20 & Civil war & $39.74 \%$ \\
21 & Electricity & $36.74 \%$ \\
22 & Agriculture & $36.04 \%$ \\
23 & Transportation & $35.18 \%$ \\
24 & Democracy & $24.31 \%$ \\
25 & Economic growth & $16.31 \%$ \\
26 & Hospital & $15.12 \%$ \\
27 & Manufacturing & $13.78 \%$ \\
28 & Climate change & $11.81 \%$ \\
29 & Tourism & $8.98 \%$ \\
30 & Corruption & $8.61 \%$ \\
31 & Reconstruction & $7.75 \%$ \\
32 & Housing & $7.65 \%$ \\
33 & Job creation & $3.50 \%$ \\
34 & Banking system & $0.00 \%$ \\
\hline & & \\
\hline & &
\end{tabular}

view. Nevertheless, Childreach is at the top of the list. According to our rankings, the average level of consistency is $59.2 \%$ of the theoretical maximum described above. 
Table 9 shows the ranking of countries. Here we used the issue consistency meaning that we look at the issues that are salient in the country and ask whether the organizations that are involved with the country also find those issues salient. There is a very broad distribution of values between countries of different sizes, regions and levels of development at both ends of the list. In this case, the average level of consistency is $62.1 \%$ of the theoretical maximum.

Table 10 shows the ranking of issues. Here we use the organizational consistency, meaning that we look at the organizations that find the issues salient and ask whether they are involved in the countries that are also strongly linked to those issues. Here the issues that have to do with poverty such as malnutrition, poverty reduction, humanitarian assistance and infant mortality appear high on the list, while the issues that deal with economic growth, such as banking systems, job creation or manufacturing, are at the bottom. Interestingly, environmental sustainability appears to be better coordinated than global warming, while human rights, technological development and gender appear in the middle of the list. For the issues, we observe an average consistency equal to $61.4 \%$ of the theoretical maximum.

\section{Concluding Remarks}

International development is a highly complex global enterprise that must confront coordination problems of paramount proportions. Since World War II, the proliferation of states, organizations and issues has created a space that is large, complex and rapidly evolving. In this paper we have developed a method that leverages the vast amount of information available on the web to measure the tripartite network connecting countries, organizations, and issues, and use it to estimate the degree of coordination that the world has, de facto, been able to achieve.

Given a set of countries and an evolving set of issues, coordination requires the ability of organizations to adapt either the portfolio of countries that they serve, or the issues they work on. Our measures indicate that the international aid network has indeed achieved a significant level of de facto coordination, as expressed in their online speech. Our methods, however, show that in many cases coordination is low, highlighting countries that are poorly served, issues that are not well attended, and organizations that appear to be focusing on the wrong combination of places and issues. Donors and recipients can use the tools and information we developed in this paper and in the Aid Explorer, the associated web application, to identify, in a decentralized manner, areas for improvement. 
During the 1980s and 1990s, aid coordination was led by the World Bank. Since then, the de jure approach to aid coordination has changed and it is now based on the Millennium Development Goals (2000), the Paris Declaration for Aid Effectiveness (2005) and the Accra Agenda for Action (2008). It implies a major effort at decentralizing decision-making by giving a more prominent role to recipient national governments. The idea is that these governments should develop their own poverty reduction strategy in accordance with the MDGs and these strategies should be the basis for a formal coordination process organized through consultative groups and roundtables.

This approach has the advantage of increasing the number of coordinators (from say one - i.e., The World Bank - to the number of recipient governments), thus reducing the amount of coordination that each must achieve, but it still leaves quite a complex task. After all, there are hundreds of aid organizations, hundreds of recipient state and local governments, dozens of executing agencies and dozens of issues that need to be paired.

Under these conditions, self-organizing processes may exhibit some distinct advantages. First, they require little ex ante explicit coordination. Second, they have the power to reveal information about emerging needs and organizational expertise. Third, they can deal with levels of complexity that strict hierarchies have trouble coping with. Yet, self-organizing processes also have limitations, since they need to satisfy some basic requirements for them to be able to operate properly.

First and foremost is information: donors must be able to know what recipients want and what other donors are willing to supply. Recipients must be able to know what donors are willing to provide and what they might be willing to consider. If donors had this information, and if they were focused on maximizing the bang of their development bucks, given whatever goals or preferences they have, they will naturally move towards the needs that are least attended among those that they care about. By the same token, if a recipient country knew about the willingness of each donor to support different activities they would adjust their priorities and partnerships to achieve maximum effect, given their preferences. So information is key for the self-organizing process to be efficient.

Second, a system based on matches between willing donors and willing recipients is bound to increase the number of transactions, and if these have very large transaction costs, then it might be better to forgo this option in favor of a more centralized process that avoids the multiplicity of transactions. The international development community has de facto understood this problem and the Accra Agenda for Action calls for streamlining procurement rules and reporting standards in order to reduce the recipient's transactions costs associated with working with multiple partners. 
In this context, a system that highlights the countries that are being poorly served, the issues that are inadequately attended and the organizations that have an imbalance between their goals and their partners may allow the different players of the aid community to improve their effectiveness without the need for a central planner. Such a system may allow supply and demand to find each other more quickly and for organizations and countries to change strategies more dynamically in the face of new information. This paper presents a very crude first approach to collect the data, and develop the analytics, that would inform such a system.

Our approach does approximate what is required for decentralized coordination because it facilitates the identification of the issues and countries that organizations care about and the issues that countries care about. Our metrics can be used as "prices" that facilitate unrealized matches between willing donors and recipients: Organizations and countries will seek to interact with partners that share interests, in the same way as in the market the equilibrium involves matching willing sellers with willing buyers. The coordination occurs ex post through the matching process rather than ex ante through some assignment of roles and tasks, something that is very hard to achieve given the large number of possible combinations and the fact that donor agencies are not hierarchically related and so need not follow each other's orders. Our associated website, The Aid Explorer, should be useful in identifying potential new matches and hence accelerate the decentralized coordination process.

While our approach is an approximation, it could be much improved. For example, we have queried only pairs and not triplets or quadruplets. We were deterred from this more exhaustive approach by the limitations imposed by public APIs and by out of pocket search costs of such an endeavor, given the constraints of academic research. But a system that is supposed to guide hundreds of billions of dollars of support should find the additional costs of better data quite insignificant. Moreover, if the data gathering process was done continuously, time resolution could be improved. In addition the issues that the analysis considers may emerge from "word cloud" analysis of the organizations' websites, rather than from a manually curated list. Finally, the number of organizations, both on the donor and the recipient sides, could be greatly expanded. While we believe that our simplified approach has shown that it has value as a proof-ofconcept, a full implementation of the above agenda would transform it into a comprehensive tool for professional and institutional use.

One word of caution that needs to be considered is the possibility that organizations will try to game the rankings provided by a system that is based mostly on the collection of online data. In a world where the expression of an organization in the web is considered an important indicator of their development expertise, 
there are clear incentives for an organization to cheat by focusing on "making noise" about development assistance instead of actually providing it. Ultimately, organizations looking to get ahead of others might try to inundate the web with documents that mention the keywords used in the data collection process. While this is an important caveat for the future applicability of these methods, it is important to note that this caveat does not apply exclusively to the methods presented in this paper. In fact, the incentive to focus on providing signals, instead of performing actions, will always be present in a world where it is hard to attribute outcomes to individual actors.

The methodology we developed in this paper can be applied to other contexts. The most similar situation is that of private foundations and their recipients. Much more ambitious would be the analysis of the interactions between government agencies and between these and the other social organizations such as corporations, unions and other non-governmental entities. Here, governments manage $\sim 10^{6}$ pages of legislations and $\sim 10^{3}$ executing agencies. They face hundreds of thousands of organizations that are affected by this complex hyperspace. Under these conditions, there must be many Pareto improvements that are impeded by the information problem that this structure faces. Tools that relax this information problem by exploiting the web may allow for a more efficient decentralized coordination in complex social systems.

\section{References}

Balassa, B. (1965) “Trade Liberalisation and Revealed Comparative Advantage," The Manchester School, 33:99-123.

Büttcher, S., C. L. A. Clarke and G. V. Cormack (2010) Information Retrieval - Implementing and Evaluating Search Engines. Cambridge, MA, USA: MIT Press.

Cohen, A. M., W. R. Hersh, C. Dubay and K. Spackman (2005) "Using Co-Occurrence Network Structure to Extract Synonymous Gene and Protein Names from MEDLINE Abstracts," BMC Bioinformatics, 6:103.

Coscia, M. and V. Rios (2012) "Knowing Where and How Criminal Organizations Operate Using Web Content.," Proceedings of the 21st ACM Conference on Information and Knowledge Management, CIKM, ACM, pp. 1412-1421.

Easterly, W. (2007) “Was Development Assistance a Mistake?,” American Economic Review, 97(2):328-332.

Geng, L. and H. J. Hamilton (2006) “Interestingness Measures for Data Mining: A Survey,” Journal ACM Computing Surveys (CSUR), 38(3):1-32.

Hagmann, P., L. Cammoun, X. Gigandet, R. Meuli, C. J. Honey, V. J. Wedeen and O. Sporns (2008)

“Mapping the Structural Core of Human Cerebral Cortex," PLOS Biology, 7:e159.

Hayek, F. (1929/1933) Monetary Theory and the Trade Cycle. London: Jonathan Cape.

Hayek, F. (1945) “The Use of Knowledge in Society," American Economic Review, XXXV (4): 519-530. American Economic Association. 
Hidalgo, C. A., B. Klinger, A.-L. Barabási and R. Hausmann (2007) “The Product Space

Conditions the Development of Nations," Science, 317(5837):482-487.

Jost, L. (2006) "Entropy and Diversity," Oikos, 113(2):363-375.

Kipling, R. (1899) The White Man's Burden. New York, NY USA: McClure's.

Kornai, J. and T. Liptak (1965) “Two-level Planning,” Econometrica, 33:141-169.

Kornai, J. (1992) "The Postsocialist Transition and The State: Reflections in the Light of Hungarian Fiscal Problems," American Economic Review, American Economic Association, 82(2):1-21.

Kruskal, J. B. (1956) "On the Shortest Spanning Subtree of a Graph and the Traveling Salesman Problem," Proceedings of the American Mathematical Society, 7(1):48-50.

Lange, O. (1949) "The Practice of Economic Planning and the Optimum Allocation of Resources," Econometrica, 17:166-171.

Lee, S. H., P.-J. Kim, Y.-Y. Ahn and H. Jeong (2010) "Googling Social Interactions: Web Search Engine Based Social Network Construction," PLoS ONE, 5(7):e11233.

Madisson, A. (2008) "Shares of the Rich and the Rest in the World Economy: Income Divergence between Nations, 1820-2030," Asian Economic Policy Review, 3(1):67-82.

Moore, M. H. (1997) Creating Public Value: Strategic Management in Government. Cambridge, MA, USA: Harvard University Press.

Newman, M. E. J. (2003) “The Structure and Function of Complex Networks," SIAM Review, 45:167-256.

Newman, M. E. J. (2010) Networks: An Introduction. New York, NY: Oxford University Press, Inc.

Pritchett, L. (1997) “Divergence, Big Time,” Journal of Economic Perspectives, 11(3):3-17.

Shannon, C. E. (1948) “A Mathematical Theory of Communication," Bell System Technical Journal, 27(3):379-423.

Sistrom, C. L. and Garvan C. W. (2004) “Proportions, Odds, and Risk,” Radiology, 230(1):12-19. 